\title{
2D metal oxide nanoflakes for sensing applications: Review and perspective
}

\author{
A. Petra Dral, Johan E. ten Elshof* \\ Inorganic Materials Science, MESA + Institute for Nanotechnology, University of Twente, P.O. Box 217, 7500 AE Enschede, The Netherlands
}

\section{A R T I C L E I N F O}

\section{Keywords:}

Two-dimensional

Metal oxide

Nanosheet

Biosensor

Gas sensor

Hierarchical architecture

\begin{abstract}
A B S T R A C T
In this review the state of the art and future prospects of 2-dimensional (2D) metal oxide nanoflakes used as active sensing elements for the detection of solutes, gases and radiation are discussed. 2D material geometries are particularly interesting for sensing applications because they provide large specific surface areas and are suitable for crystal facet engineering. In addition, unique material properties of atomically thin nanosheets due to quantum size effects provide engineering possibilities beyond the realm of their bulk counterparts. A variety of possibilities in materials, synthesis routes, (hierarchical) sensor architectures and application areas is sketched. The discussion is focused on high-performing sensors and innovative concepts. The scope is limited to nanoflakes with a thickness of up to $50 \mathrm{~nm}$. Special attention is given to sensing based on material properties that are unique to atomically thin nanosheets.
\end{abstract}

\section{Introduction}

Many industries and day-to-day technologies rely on sensors for safety, quality control and analysis. Sensors are required to detect i.e. specific gases, biomolecules or radiation with sufficient sensitivity, selectivity, speed and stability (' $4 S$ ' requirements). Using 2D sensing elements has several advantages as opposed to using bulk 3D units of the same material. Freestanding 2D nanoflakes have a large specific surface area, which enables extensive interaction with the environment even for small amounts of material. Also, rigid 2D building blocks can facilitate an open packing in 3D assemblies when they are immobilized in a non-stacking fashion. In comparison with 3D architectures derived from $1 \mathrm{D}$ or $\mathrm{OD}$ components, 2D-in-3D architectures can provide more efficient electron transport because of fewer grain boundaries and they also tend to have a better mechanical stability [1,2]. Using 2D subunits furthermore allows tuning of the surface reactivity and selectivity via crystal facet engineering $[1,3,4]$. In addition, unique material properties of atomically thin nanosheets due to quantum size effects, e.g. the increased band gap energy of $\mathrm{TiO}_{2}$ nanosheets [5] and the visible light absorption of $\mathrm{MnO}_{2}$ nanosheets [6], provide engineering possibilities beyond the realm of their bulk counterparts. To date, literature reports occasionally describe such unique intrinsic material properties for metal oxide-based sensing, but most often the 2D concept is interpreted only from a geometric viewpoint (increased surface area).

In the past year many reviews have been published on a variety of 2D materials for sensing applications. Zhang et al. [7], Bo et al. [8], Campuzano et al. [9], Zhang et al. [10], Fu et al. [11] and Xu et al. [12] reviewed 2D graphene-based sensors, mostly employing electrochemical mechanisms and for biological applications. Wang et al. did the same and also included 2D transition metal dichalcogenides, graphite carbon nitride and boron nitride [13]. Bollella et al. furthermore included 2D transition metal oxides [14]. A review focusing on 2D transition metal dichalcogenides for sensors was published by Ping et al. [15]. Yang et al. [16] and Liu et al. [17] published a review focusing on gas sensors, describing various sensor devices and synthetic methods and including 2D graphene-based materials, metal (di)chalcogenides, phosphorene, boron nitride, MXenes and metal oxides. Given the yearly number of publications on 2D metal oxides as sensing elements, indicated in Fig. 1, the present review is devoted particularly to 2D metal oxide sensors. The classification in gas, solute and radiation sensors reflects the available literature and was not used to limit the literature search.

The present review discusses the state of the art and future prospects of 2D metal oxide nanoflakes used as active sensing elements. Most of the publications on 2D metal oxide sensors are proof-of-concept reports demonstrating a variety of possibilities without yet reaching competitive performances. These studies will be summarized shortly to sketch the variety of possibilities in materials, synthesis routes, (hierarchical) sensor architectures and application areas. The discussion is focused on highly sensitive sensors and innovative concepts. Notes on sensor selectivities are included as well, but sensor speed and stability (other ' $4 \mathrm{~S}$ ' requirements) are left out of scope. Special attention is given to sensing based on material properties that are unique to atomically thin nanosheets. The outline of this review is as follows. In Section 2 a variety

\footnotetext{
* Corresponding author.

E-mail addresses: a.p.dral@alumnus.utwente.nl (A.P. Dral), j.e.tenelshof@utwente.nl (J.E. ten Elshof).
} 


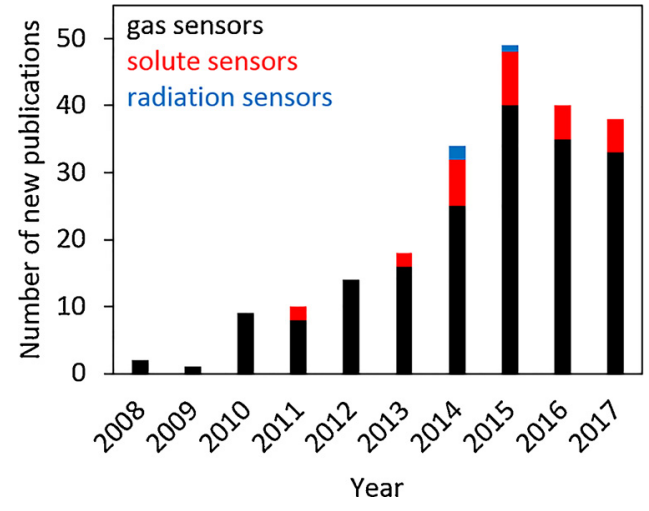

Fig. 1. Indication of the number of new publications per year on sensors with 2D metal oxide nanoflakes of up to $50 \mathrm{~nm}$ thick as active sensing elements. The numbers are based on the literature references in Table 1 and 4 and Section 5.

of 2D-based metal oxide architectures and synthesis routes is introduced and described. In Section 3 the use of 2D metal oxide nanoflakes for sensing of solutes is discussed, including sensing mechanisms, used materials and reported sensor performances. The same aspects are discussed for 2D metal oxide nanoflakes for gas sensing in Section 4, with specific attention for rational design approaches. In Section $52 \mathrm{D}$ metal oxide nanoflakes for sensing of radiation are discussed. In Section 6 a perspective is given on future development and optimization of sensor devices.

\section{2D-based architectures and their synthesis}

\subsection{Architectures}

2D nanoflakes can be employed as active sensing elements both individually and incorporated in 3D architectures. Individual nanoflakes are difficult to handle and are thus mostly employed for sensing in suspended form to detect solutes. Examples of a few-nm thin flexible nanoflake and a stack of rigid nanoflakes of 10-15 nm thickness are shown in Fig. 2a-b $[18,19]$. The majority of reports employing 2D nanoflakes as active sensing elements do so by incorporating the nanoflakes in porous 3D architectures. This ensures good exposure of the 2D surfaces to the environment with proper gas diffusion through the assembly. The most common architectures are flower-like structures as shown in Fig. 2c-d [20,21], in which the nanoflakes form a highly porous sphere and are oriented perpendicular to the sphere surface, i.e. emanating from the core. The nanosheets may self-assemble spontaneously or can grow on pre-existing cores. In the tree-like structures of Fig. 2e [22] the nanoflakes are standing on the outer surface of nanorods or tubes (trunks). Nanoflakes vertically standing on a flat substrate form nanowalls as in Fig. 2f [23]. Densely packed nanowalls or randomly oriented nanoflakes can be categorized as nanoforests, shown in Fig. $2 \mathrm{~g}$ [24]. Films included in this review are not continuous but consist of 2D subunits (crystallites), i.e. layers of nanoflakes that horizontally cover a flat substrate or layers of aggregated nanoflakes without a particular order. The difference between walls, forests and films is somewhat arbitrary. In general it is important that gas molecules can easily diffuse to the active surface, i.e. too densely packed architectures may lose effectiveness.

2D nanoflakes in 3D assemblies generally require a thickness of several $\mathrm{nm}$ or more in order to have sufficient mechanical strength to sustain an open architecture under dry conditions. This is usually achieved via bottom-up syntheses and can yield continuous single crystals, but 2D nanoflakes may also consist of $0 D[25,26]$ or $1 D$ $[27,28]$ subunits. Meso- and macropores can be created in the nanoflakes e.g. by a loose connection of OD subunits [26] or during oxidation or annealing of non-porous precursor nanoflakes [29-31]. Scanning electron microscopy and transmission electron microscopy images of 2D nanoflakes with meso- and macropores are shown in Fig. $3[2,32]$. Porosity facilitates diffusion of target species in the sensing architecture and can increase the surface area.

\subsection{Synthesis of $2 D$ nanoflakes}

The majority of the 2D nanoflakes is synthesized via hydrothermal or solvothermal procedures. Common advantages of hydrothermal and
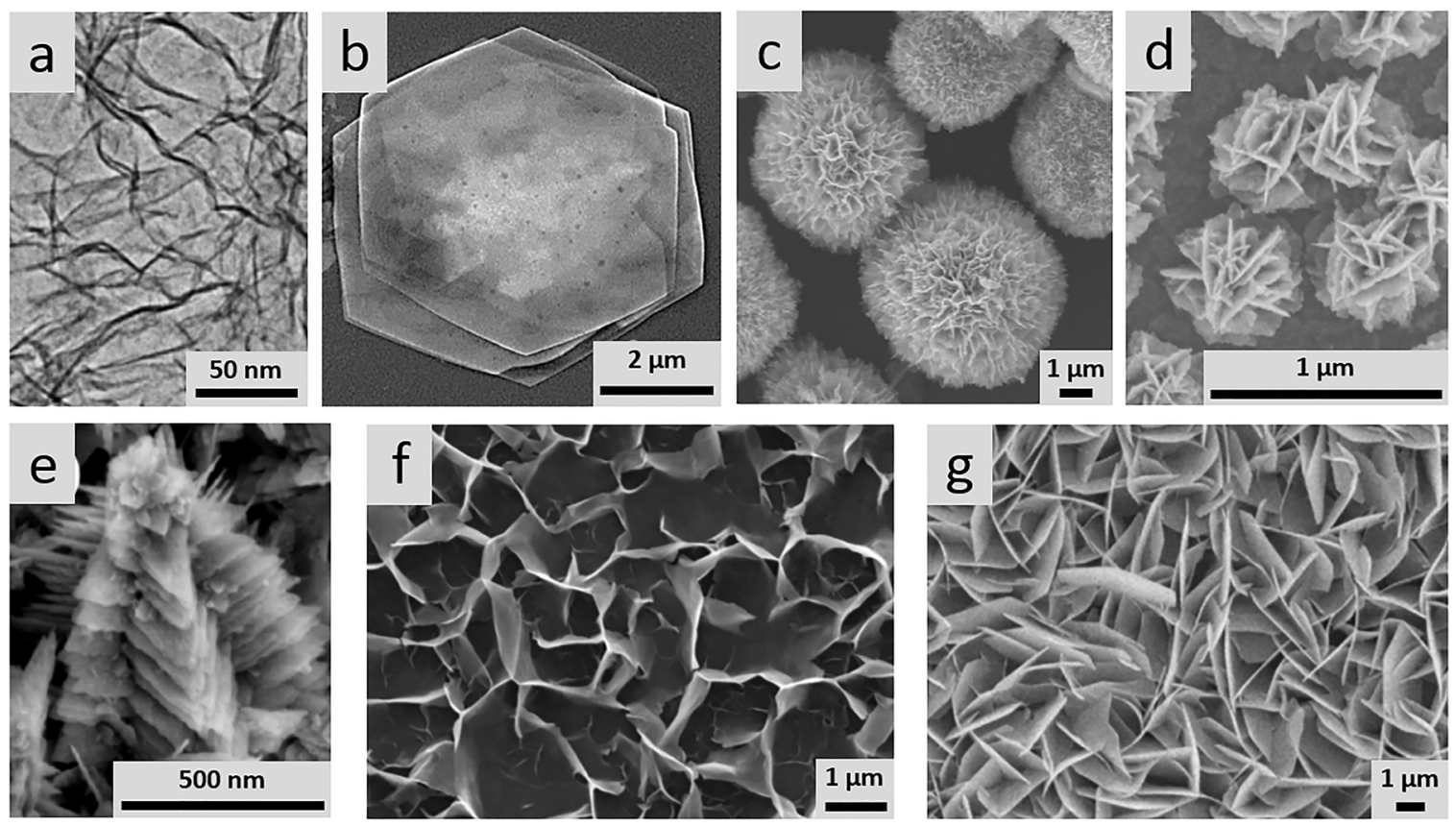

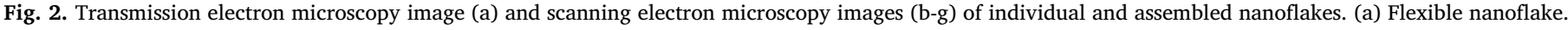

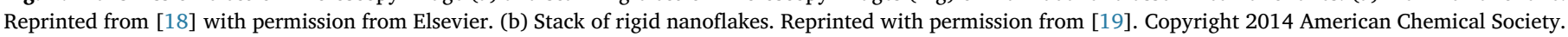

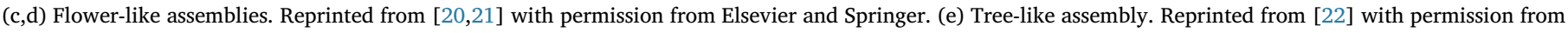
Elsevier. (f) Walls. Reprinted from [23] with permission from Elsevier. (g) Forest. Reprinted from [24] with permission from Elsevier. 

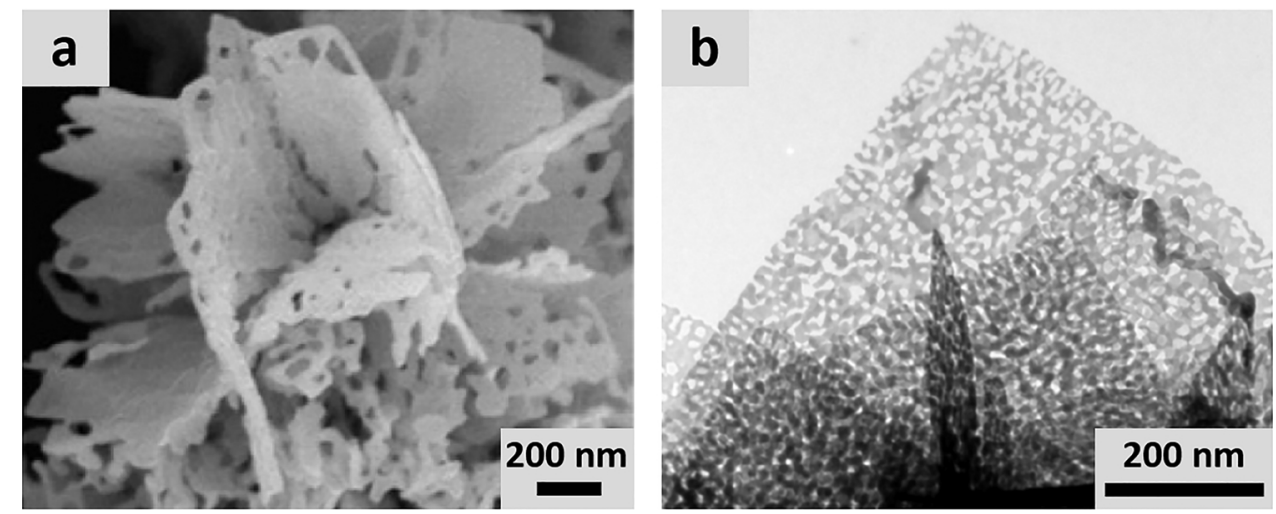

Fig. 3. (a) Scanning electron microscopy image of meso- and macropores in $2 \mathrm{D}$ nanoflakes of $\mathrm{SnO}_{2}$. Reprinted from [32] with permission from Elsevier. (b) Transmission electron microscopy image of mesopores in 2D nanoflakes of $\mathrm{SnO}_{2}$. Reprinted from [2] with permission from Elsevier.

solvothermal syntheses are simplicity, scalability, low costs, low processing temperatures and compatibility with flexible substrates. Metal oxide precursors are dissolved in water or an organic solvent and the reaction typically takes place at temperatures of $75-200^{\circ} \mathrm{C}$ with reaction times of 3-12 h, sometimes extended up to a few days. Common precursors are e.g. metal chlorides, sulfates, nitrates and acetates. For 2D-in-3D hierarchical architectures, the metal oxide may grow in the desired structure spontaneously [33-37] or structure-directing agents such as cetyltrimethylammoniumbromide [38-41], glycerol [39,42], hexamethylenetetramine [23,43-45], polyvinylpyrrolidone $[2,40,46,47]$, urea $[25,40,48,49]$, sodiumdodecylsulfate [50-52] or polyethyleneglycol [52-55] can be added. Also, seed layers may be employed to initiate growth $[23,24,43,44,56]$ and occasionally microwave-assisted procedures are used [57,58]. After the 2D-in-3D architecture is obtained, annealing at $250-500{ }^{\circ} \mathrm{C}$ may be required for decomposition of organic residues, dehydroxylation or crystallization. Procedures without annealing are also possible [35,53,59,60]. In some cases the 3D architecture is obtained for sulfide intermediates such as $\mathrm{In}_{2} \mathrm{~S}_{3}, \mathrm{MoS}_{2}$ or $\mathrm{SnS}_{2}$, which are then converted into the corresponding metal oxide by thermal oxidation [29,61,62]. An uncommon type of hydrothermal fabrication has been reported for $\mathrm{ZnSnO}_{3}$ structures, involving the hydrothermal dissolution of $3 \mathrm{D}$ cubes and subsequent recrystallization into 2D nanoflakes [63].

Alternative synthesis approaches include room-temperature solution procedures, reported for e.g. $\mathrm{ZnO}$ [64-66] and $\mathrm{MnO}_{2}$ [38,67]. Room-temperature sonochemical procedures followed by thermal annealing have been reported for flowers of $\mathrm{WO}_{3}$ [68] and $\mathrm{Fe}_{2} \mathrm{O}_{3}-\mathrm{NiO}$ [69]. The $\mathrm{WO}_{3}$ flowers were synthesized from $\mathrm{Na}_{2} \mathrm{WO}_{4}$ in aqueous solution with oxalic acid as capping agent, while the $\mathrm{Fe}_{2} \mathrm{O}_{3}-\mathrm{NiO}$ flowers were derived from a coordination polymer precursor with polyethyleneglycol as surfactant. Coordination polymer precursors provide an easy route to multicomponent mixed metal oxides with high composition uniformity $[69,70]$. Electrodeposition has been reported as a method to prepare $\mathrm{Ni}$ flowers that can subsequently be oxidized to $\mathrm{NiO}$ [21,71]. $\mathrm{ZnO}$ nanoforests and $\mathrm{TiO}_{2}$ nanowalls have been obtained by oxidation of corresponding metal films [72,73]. 2D metal oxide nanoflakes of only a few nm thickness can be obtained by chemical exfoliation from layered parent compounds, reported for e.g. $1 \mathrm{~nm}$ thick $\mathrm{RuO}_{2}$ [74], $4 \mathrm{~nm}$ thick $\mathrm{MoO}_{3}$ [75-77] and $\mathrm{WO}_{3}$ [78]. Exfoliation can be assisted by e.g. mild mechanical shaking or sonication and the nanoflakes can be used individually in suspension or be processed into films. More elaborate descriptions of the exfoliation of 2D metal oxides can be found elsewhere [17,79].

The synthesis route determines whether the formed 2D nanoflakes are single-crystalline or polycrystalline and this can profoundly influence the sensor performance. Crystal grain boundaries contain large numbers of surface states that can trap or scatter free charge carriers, which increases the effective resistivity [80]. Single crystalline nanoflakes tend to have better stability at elevated temperatures due to reduced grain coalescence and resulting alterations of grain boundaries and porosity [81]. Other important synthesis aspects are the obtained crystal orientation and surface morphology, as discussed extensively elsewhere [82]. 2D geometries are particularly suitable for crystal facet engineering.

\section{2D nanoflakes for solute sensing}

\subsection{Sensing mechanisms}

For sensing of solutes, 2D nanoflakes can be immobilized on a support or be used in suspended form. Nanoflakes in suspension can function as individual sensors even if they are only a few atoms thick. Target species in solute sensing are often biomolecules, which can be immobilized onto nanoflakes via e.g. non-specific Van der Waals forces and electrostatic interactions. Sensing based on non-specific interactions is not favorable when analyzing mixtures of biomolecules. In contrast, very high selectivities can be reached for nanoflakes decorated with signaling moieties that interact with the target molecules via e.g. DNA or peptide recognition [38,83,84]. Adsorption-based sensing of solutes often only involves turn-on sensing; once the target molecules are bound by the sensing platform, they do not detach spontaneously anymore. If the nanoflakes are immobilized on a support, regeneration may be possible to enable reuse of the sensor.

Adsorption events can be detected via e.g. fluorescent, plasmonic and/or chemiresistive signals. In fluorescent sensors, light-absorbing metal oxides generally quench the fluorescence of adsorbed signaling species. Upon interaction of the signaling species with the target molecule, e.g. via DNA hybridization, the signaling species (partially) desorbs and the dye label escapes from the quenching influence of the metal oxide nanoflakes, thus retaining its fluorescence [38,83,84]. Alternatively, the fluorescent signaling species can be released via consumption of the metal oxide nanosheets in oxidation reactions with the target species $[67,85]$.

Plasmonic sensors exploit the sensitivity of surface plasmons in metal oxide nanoflakes towards electrical interactions with adsorbed species. The adsorption of charged species causes a change in the free electron density at the surface of the metal oxide, which affects the intensity of plasmonic absorption [75]. Plasmonic sensing particularly benefits from 2D sensing elements, because the existence of one large depolarization factor in 2D geometries reduces the plasmon resonance wavelength as compared to 1D geometries that have two modest depolarization factors [75]. This can shift the resonance wavelength into the visible light and infrared region, which is important for applications as these wavelengths are commonly used in optical systems [75]. A 
a)

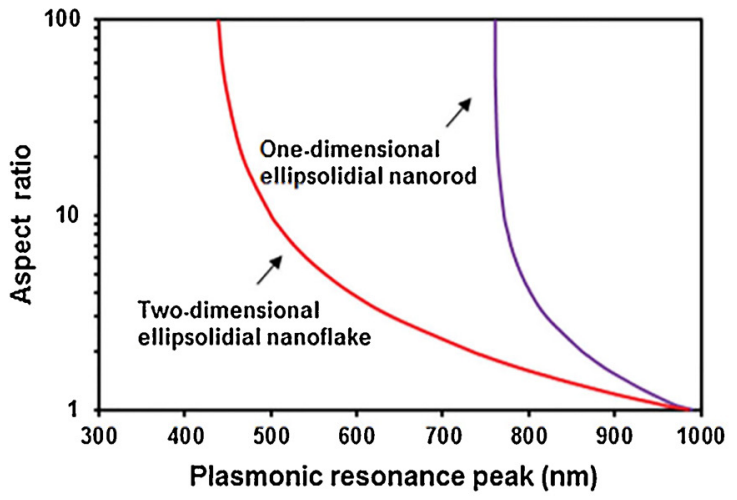

b)
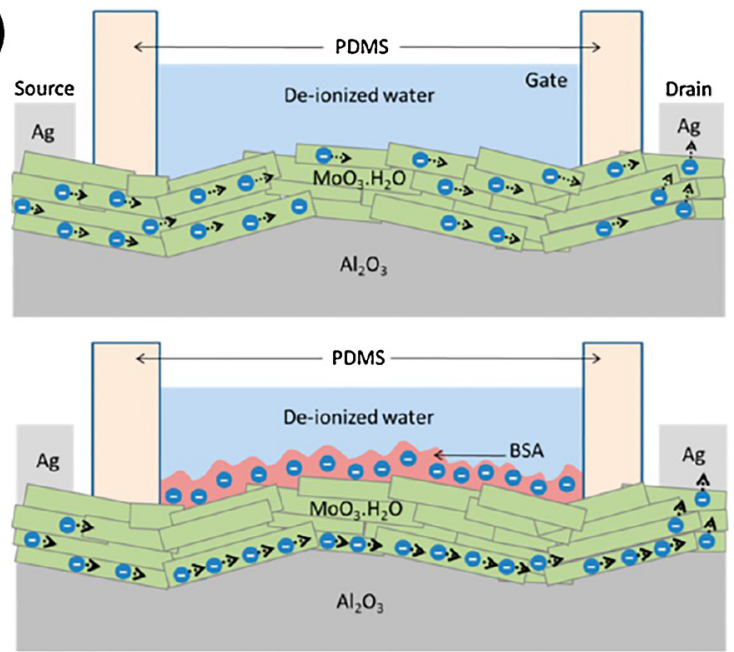

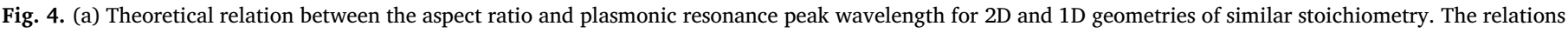

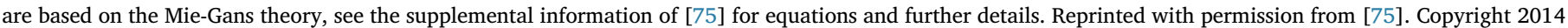

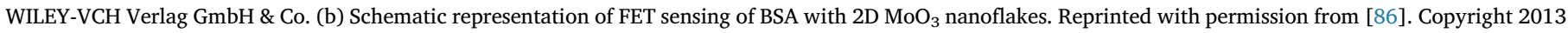
American Chemical Society.

schematic representation of the theoretical relation between the aspect ratio and plasmonic resonance peak wavelength for $2 \mathrm{D}$ and $1 \mathrm{D}$ geometries of similar stoichiometry is shown in Fig. 4a [75].

An example of field-effect transistor (FET) solute sensing employing a film of 2D metal oxide nanoflakes as conduction channel is given in Fig. 4b [86]. The electrical conductivity of the channel varies with the adsorption of target molecules on its surface. In Fig. 4b the adsorption of negatively charged bovine serum albumin (BSA) molecules creates a negative potential on the surface of the n-type semiconductor $\mathrm{MoO}_{3}$ nanoflake film, which increases the channel resistance.

As an alternative to adsorption-based sensing, solutes may also be detected via electrochemical reactions. Oxidation or reduction of the target species at a nanoflake-covered electrode yields an electric current or potential as response. Electrochemical sensors are especially employed for glucose detection. Drawbacks of commonly used glucose sensors based on enzymes are their poor stability, high cost and weakness to environmental conditions [87], which can be circumvented by non-enzymatic electrochemical sensing.

\subsection{Materials}

An overview of literature reports on 2D metal oxide nanoflakes that have served as active sensing element for solutes is given in Table 1, indicating the used materials, architectures, syntheses, 2D thicknesses, target species and underlying sensing mechanisms. Individually suspended 2D nanoflakes for sensing generally have a layered structure with a thickness of only a few unit cells. An advantage of layered structures is the possibility of ionic intercalation, which allows very high dopant concentrations (ultradoping) [75]. Ultradoping can increase the free carrier concentration in semiconductors to such an extent that plasmonic resonances shift towards the near-infrared and visible light regions [88]. Metal oxides suitable for plasmonic sensing are e.g. $2 \mathrm{D} \mathrm{MoO}_{3-\mathrm{x}}$ and $\mathrm{WO}_{3-\mathrm{x}}$, both of which benefit from having large dielectric constants and are capable of accommodating ultradoping $[75,76,89]$. For few-nm $\mathrm{MoO}_{3}$ nanoflakes, irradiation with solar light in the presence of water causes intercalation of the layered structure with $\mathrm{H}^{+}$ions and partially reduces Mo. This results in more oxygen vacancies and causes a transition from semiconducting $\alpha-\mathrm{MoO}_{3}$ to metallic $\mathrm{Mo}_{4} \mathrm{O}_{11}$. Fig. 5 shows UV/visible light absorption spectra of 2D $\mathrm{MoO}_{3}$ nanoflakes before and after solar light irradiation, demonstrating the appearance of an absorption band in the near-infrared/visible light region that blue-shifts with increasing irradiation time [75].
Fluorescent sensors require light-absorbing materials such as $\mathrm{MoO}_{3}$ and $\mathrm{MnO}_{2}[38,67,83,84]$ to quench the fluorescence of the signaling species. Most 2D transition metal oxides show intensive light absorption due to strong $d$ - $d$ transitions [109]. Metal oxides can be beneficial for fluorescent sensing as compared to metal sulfides and selenides because the oxygen atoms yield stronger electrostatic interactions with the signaling species, which causes closer proximity and more efficient quenching [84]. An advantage of atomically thin $\mathrm{MnO}_{2}$ nanoflakes is that they are also strongly oxidative towards organic compounds and this feature can be employed in combination with their light absorption $[67,85]$.

Electrochemical sensors require metal oxides that are oxidative or reducing towards the target species. Many 2D transition metal oxides have high isoelectric points, which facilitates the immobilization and subsequent charge transfer for a wide range of biomolecules with lower isoelectric points $[109,110]$. NiO is used for electrochemical glucose sensors because of its low cost, good electrocatalytic activity, biocompatibility and electron transfer capability $[25,100]$. The absence of poisoning by oxidation products under alkaline conditions enables repeated usage of NiO-based sensors [111]. Other electrochemically active materials are $\mathrm{Ni}(\mathrm{OH})_{2}$, which is also a precursor for $\mathrm{NiO}$, and $\mathrm{CuO}$ and $\mathrm{Co}_{3} \mathrm{O}_{4}[28,90,103,106]$.

\subsection{Performance}

\subsubsection{Glucose sensors}

Most glucose sensors are based on non-enzymatic electrochemical detection with 2D NiO, $\mathrm{Ni}(\mathrm{OH})_{2}, \mathrm{CuO}$ and $\mathrm{Co}_{3} \mathrm{O}_{4}$ nanoflakes, of which the performances are summarized in Table 2. The lowest detection limits $(<1 \mu \mathrm{M})$ and linear response onsets $(1 \mu \mathrm{M}$ with a window up to several thousand $\mu \mathrm{M})$ have been reported for $\mathrm{Ni}(\mathrm{OH})_{2}$ sensors $[101,103,104]$. The highest sensitivity has been reported by Cui et al., reaching over $30 \mathrm{~mA} \mathrm{mM}^{-1} \mathrm{~cm}^{-2}$ with flower-like structures of $\mathrm{NiO}$ on a core of carbon [25]. The addition of urea, ascorbic acid, L-leucine, Llysine and $\mathrm{NaCl}$ did not significantly interfere with the glucose signal. The widest linear response range has been reported by Ngo et al. using $\mathrm{NiO}$ flowers on a film of reduced graphene oxide and decorated with $\mathrm{Ag}$ particles [100]. The sensitivity was $1.9 \mathrm{~mA} \mathrm{mM}^{-1} \mathrm{~cm}^{-2}$ in the linear response region of $50 \mu \mathrm{M}-7.5 \mathrm{mM}$ and $116 \mu \mathrm{AmM}^{-1} \mathrm{~cm}^{-2}$ in the linear response region of 10-25 mM. No significant interference was observed from uric acid, ascorbic acid, dopamine, fructose, lactose and sucrose. Solute interference can be suppressed not only by tuning the sensor 
Table 1

Overview of literature reports on 2D metal oxide nanoflakes that have served as active sensing element for solutes. Syntheses denoted as 'hydrothermal' include at most $50 \%$ organic solvent. Syntheses denoted as 'solution' include temperatures up to $45^{\circ} \mathrm{C}$.

\begin{tabular}{|c|c|c|c|c|c|c|}
\hline Reference & 2D metal oxide & Architecture & Synthesis & $\begin{array}{l}\text { 2D thickness } \\
{[\mathrm{nm}]}\end{array}$ & Target species & Sensing mechanism \\
\hline [90] & $\mathrm{Co}_{3} \mathrm{O}_{4}$ & aggregate with $\mathrm{Ni}(\mathrm{OH})_{2}$ & solvothermal & $5-15$ & glucose & electrochemical \\
\hline [28] & $\mathrm{CuO}$ & random film of stacked flakes & solution & $20-40$ & glucose & electrochemical \\
\hline [38] & $\mathrm{MnO}_{2}$ & flower decorated with dye-labeled ssDNA & solution & 4 & ssDNA & fluorescent \\
\hline [67] & $\mathrm{MnO}_{2}$ & individual flake decorated with 7-hydroxycoumarin & solution & 1 & ascorbic acid & fluorescent \\
\hline [85] & $\mathrm{MnO}_{2}$ & $\begin{array}{l}\text { individual flake decorated with protein-stabilized Au } \\
\text { nanoclusters }\end{array}$ & solution & probably 1 & glutathione & fluorescent \\
\hline [83] & $\mathrm{MnO}_{2}$ & $\begin{array}{l}\text { individual flake decorated with dye-labeled ssDNA or } \\
\text { peptide }\end{array}$ & solution & probably 1 & $\begin{array}{l}\text { ssDNA (ochratoxin A), } \\
\text { cathepsin D }\end{array}$ & fluorescent \\
\hline [91] & $\mathrm{MnO}_{2}$ & individual flake decorated with dye-labeled DNA & solution & 1 & microRNA & fluorescent \\
\hline [92] & $\mathrm{MnO}_{2}$ & individual flake on doped $\mathrm{NaYF}_{4}$ nanoparticles & solution & $1-3$ & $\mathrm{H}_{2} \mathrm{O}_{2}$, glucose & fluorescent \\
\hline [93] & $\mathrm{MnO}_{2}$ & individual flake on doped $\mathrm{NaYF}_{4}$ nanoparticles & solution & $1-3$ & glutathione & fluorescent \\
\hline [94] & $\mathrm{MnO}_{2}$ & individual flake on doped $\mathrm{Sr}_{2} \mathrm{MgSi}_{2} \mathrm{O}_{7}$ nanoparticles & solution & probably $1-3$ & glutathione & fluorescent \\
\hline [95] & $\mathrm{MnO}_{2}$ & individual flake decorated with C nanoparticles & solution & probably $1-3$ & glutathione & fluorescent \\
\hline [96] & $\mathrm{MnO}_{2}$ & $\begin{array}{l}\text { individual flake on phenol formaldehyde resin } \\
\text { particles }\end{array}$ & solution & $<5$ & glutathione & fluorescent \\
\hline [97] & $\mathrm{MnO}_{2}$ & individual flake decorated with Si quantum dots & solution & probably $1-3$ & glutathione & fluorescent \\
\hline [18] & $\mathrm{MnO}_{2}$ & film & solvothermal & 5 & $\mathrm{H}_{2} \mathrm{O}_{2}$ & electrochemical \\
\hline [75] & $\mathrm{MoO}_{3-\mathrm{x}}$ & individual flake & exfoliation & $4-6$ & BSA & plasmonic \\
\hline [76] & $\mathrm{MoO}_{3-\mathrm{x}}$ & individual flake & exfoliation & $4-26$ & BSA & plasmonic \\
\hline [98] & $\mathrm{MoO}_{3-\mathrm{x}}$ & flower with $\mathrm{MoO}_{3}$ surface & solvothermal & $20-30$ & methylene blue & plasmonic \\
\hline [84] & $\mathrm{MoO}_{3}$ & individual flake decorated with dye-labeled ssDNA & exfoliation & probably $1-2$ & $\begin{array}{l}\text { ssDNA (prostate-specific } \\
\text { antigen) }\end{array}$ & fluorescent \\
\hline [86] & $\mathrm{MoO}_{3}$ & film coated with $1 \mathrm{~nm} \mathrm{Au}$ & exfoliation & $1-3$ & BSA & FET \\
\hline [99] & $\mathrm{Na}_{2} \mathrm{Ti}_{3} \mathrm{O}_{7}$ & film & hydrothermal & 10 & $\mathrm{Hg}^{2+}$ & electrochemical \\
\hline [25] & $\mathrm{NiO}$ & flower on $\mathrm{C}$ core & hydrothermal & $30-50$ & glucose & electrochemical \\
\hline [100] & $\mathrm{NiO}$ & flower on RGO film and decorated with $\mathrm{Ag}$ particles & hydrothermal & $<50$ & glucose & electrochemical \\
\hline [101] & $\mathrm{Ni}(\mathrm{OH})_{2}$ & wall [102] on over-oxidized polypyrrole wires & solution & $<50$ & glucose & electrochemical \\
\hline [103] & $\mathrm{Ni}(\mathrm{OH})_{2}$ & flower & solvothermal & 5 & glucose & electrochemical \\
\hline [104] & $\mathrm{Ni}(\mathrm{OH})_{2}$ & hollow flower & hydrothermal & $<50$ & glucose & electrochemical \\
\hline [105] & $\mathrm{Ni}(\mathrm{OH})_{2}$ & flower aggregated with carbon nanotubes & solution $\left(45^{\circ} \mathrm{C}\right)$ & $<50$ & glucose & electrochemical \\
\hline [106] & $\mathrm{Ni}(\mathrm{OH})_{2}$ & forest on Ni foam & hydrothermal & 30 & glucose & electrochemical \\
\hline [107] & $\mathrm{TiO}_{2}$ & flakes and particles decorating RGO & solvothermal & $<5$ & dopamine & electrochemical \\
\hline [108] & $\mathrm{ZnO}$ & film decorated with antibodies & solution & 20 & cortisol & electrochemical \\
\hline
\end{tabular}

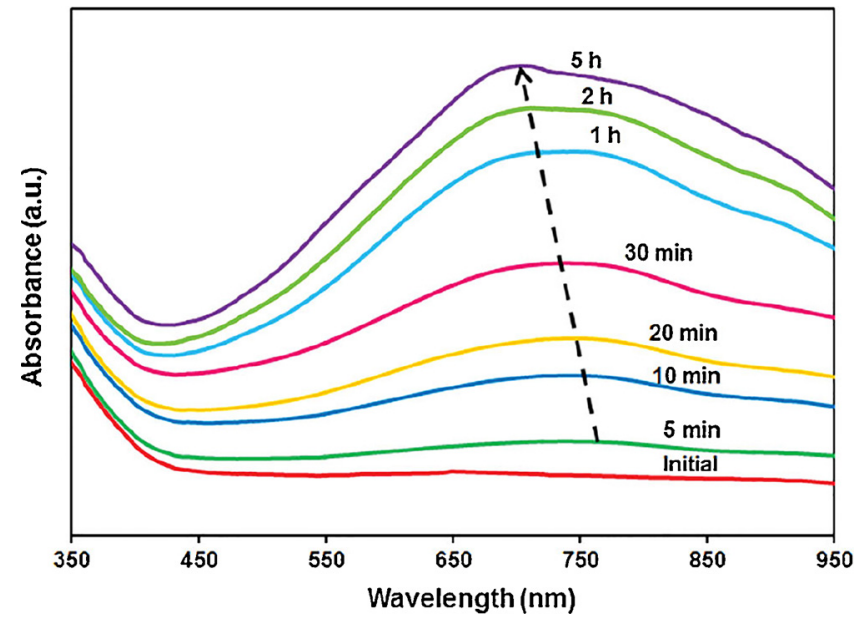

Fig. 5. UV/visible light absorption spectra of $2 \mathrm{D} \mathrm{MoO}_{3}$ nanoflakes before and after solar light irradiation. Reprinted with permission from [75]. Copyright 2014 WILEY-VCH Verlag GmbH \& Co.

design, but also by tuning the operation conditions. For example, the operation $\mathrm{pH}$ may be chosen such that major interfering species have the same charge as the sensing electrode, i.e. both negative or both positive, and are thus electrostatically repelled [106]. A fluorescent enzymatic glucose sensor employing $\mathrm{MnO}_{2}$ nanoflakes on doped $\mathrm{NaYF}_{4}$ upconversion nanoparticles has been reported by Yuan et al. [92]. Glucose was degraded by glucose oxidase, which released $\mathrm{H}_{2} \mathrm{O}_{2}$ that in turn degraded the $\mathrm{MnO}_{2}$ nanoflakes and thereby restored the fluorescence of the $\mathrm{NaYF}_{4}$ nanoparticles.
Table 2

Sensitivity per $\mathrm{cm}^{2}$ electrode surface area, lower limit of detection $(\mathrm{S} / \mathrm{N}=3)$ and concentration window of linear response for glucose sensors with 2D metal oxide sensing elements.

\begin{tabular}{|c|c|c|c|c|}
\hline Reference & $\begin{array}{l}2 \mathrm{D} \\
\text { metal } \\
\text { oxide }\end{array}$ & $\begin{array}{l}\text { Sensitivity } \\
{\left[\mu \mathrm{mM}^{-1} \mathrm{~cm}^{-2}\right]}\end{array}$ & $\begin{array}{l}\text { Lower limit of } \\
\text { detection (S/ } \\
\mathrm{N}=3 \text { ) }[\mu \mathrm{M}]\end{array}$ & $\begin{array}{l}\text { Linear response } \\
\text { window }[\mu \mathrm{M}]\end{array}$ \\
\hline [90] & $\mathrm{Co}_{3} \mathrm{O}_{4}$ & 1089 / 2145 & 1.08 & $5-40 / 40-200$ \\
\hline [28] & $\mathrm{CuO}$ & $26.6\left(\mu \mathrm{AmM}^{-1}\right)$ & 5 & $10-7300$ \\
\hline [92] & $\mathrm{MnO}_{2}$ & n.a. & 3.7 & $0-250 / 250-400$ \\
\hline [25] & $\mathrm{NiO}$ & 30190 & 2 & $2-1279$ \\
\hline [100] & $\mathrm{NiO}$ & $1869 / 116$ & 2.44 & $\begin{array}{l}50-7500 / \\
10000-25000\end{array}$ \\
\hline [101] & $\mathrm{Ni}(\mathrm{OH})_{2}$ & 1049 & 0.3 & $1-4863$ \\
\hline [103] & $\mathrm{Ni}(\mathrm{OH})_{2}$ & 419 & 0.08 & $0.87-10530$ \\
\hline [104] & $\mathrm{Ni}(\mathrm{OH})_{2}$ & 223 & 0.1 & $0.8749-7781$ \\
\hline [105] & $\mathrm{Ni}(\mathrm{OH})_{2}$ & 238.5 & 0.5 & $100-1100$ \\
\hline [106] & $\mathrm{Ni}(\mathrm{OH})_{2}$ & 2617 & 2.5 & $2.5-1050$ \\
\hline
\end{tabular}

\subsubsection{Glutathione sensors}

Glutathione sensors are typically based on composites of fluorescent probes and $\mathrm{MnO}_{2}$ nanoflakes. The $\mathrm{MnO}_{2}$ nanoflakes act both as fluorescence quenchers and as oxidizing agents; redox reactions with glutathione consume the nanoflakes and thus restore the fluorescence of the probes. This sensing mechanism only provides turn-on signals, but generally shows good selectivity towards glutathione over other biomolecules and electrolytes. Table 3 lists fluorescent probes, detection limits and concentration windows of linear response reported in literature. All detection limits are well below the typical glutathione concentration in cells $(0.5-10 \mathrm{mM}$ [112]). The linear response windows can be tuned by changing the concentration of $\mathrm{MnO}_{2}$ composites, i.e. 
Table 3

Fluorescent probe, lower limit of detection and concentration window of linear response for fluorescent glutathione sensors based on $2 \mathrm{D} \mathrm{MnO}_{2}$ nanoflakes.

\begin{tabular}{llll}
\hline Reference & Fluorescent probe & $\begin{array}{l}\text { Lower limit of } \\
\text { detection }[\mu \mathrm{M}]\end{array}$ & $\begin{array}{l}\text { Linear response } \\
\text { window }[\mu \mathrm{M}]\end{array}$ \\
\hline$[93]$ & $\begin{array}{l}\text { Yb- and Tm-doped } \\
\text { core-shell NaYF }\end{array}$ & 0.9 & n.d. \\
{$[94]$} & $\begin{array}{l}\text { Eu- and Dy-doped } \\
\mathrm{Sr}_{2} \mathrm{MgSi}_{2} \mathrm{O}_{7}\end{array}$ & 0.83 & $0-100$ \\
{$[95]$} & $\begin{array}{l}\mathrm{C} \text { nanoparticles } \\
\text { BSA-stabilized Au } \\
\text { nanoclusters } \\
\text { phenol formaldehyde } \\
\text { resin }\end{array}$ & 0.022 & $0.2-600$ \\
{$[96]$} & Si quantum dots & 0.0076 & $0-500$ \\
{$[97]$} & 0.153 & $0-100$ \\
\hline
\end{tabular}

shifting the signal baseline and saturation. Sensing with $\mathrm{MnO}_{2}$ nanoflakes has been demonstrated in living cells [93,94,97], in human whole blood [95] and in vivo without external excitation [94].

\subsubsection{BSA sensors}

Bovine serum albumin detection employing individually suspended $\mathrm{MoO}_{3-\mathrm{x}}$ nanoflakes of 4-6 $\mathrm{nm}$ thickness for plasmonic sensing has been reported by Alsaif et al. [75,76]. Initially, response factors of 1.3 and 2.1 were reported for BSA concentrations of 0.15 and $15 \mathrm{mg} \mathrm{mL}^{-1}$, respectively [75]. In following work the response factors were improved to 7 and 24 for BSA concentrations of 0.25 and $10 \mathrm{mg} \mathrm{mL}^{-1}$, respectively [76]. The response factor was found to increase with decreasing lateral flake size and thickness and with decreasing free electron concentration. No data was reported on sensor selectivities. FET-based BSA sensing with drop-cast films of $2 \mathrm{D} \mathrm{MoO}_{3}$ with a 1-1.5 nm Au coating has been reported by Balendhran et al. [86]. The Au coating was added to facilitate charge transfer between film and electrodes and to facilitate the adsorption of BSA. Resistance changes of about $1 \%$ and $30 \%$ were achieved for concentrations of 1 and $25 \mathrm{mg} \mathrm{mL}^{-1}$, respectively.

\subsubsection{Molecular recognition sensors}

DNA- or peptide-based molecular recognition of various biomolecules in suspension has been achieved with fluorescent sensors. He et al. have reported the use of $\mathrm{MnO}_{2}$ nanoflakes of approximately $4 \mathrm{~nm}$ thickness that were assembled in flower architectures and decorated with adsorbed dye-labeled ssDNA signaling species [38]. A linear relation between the fluorescence and target molecule concentration was obtained over the range of $0-5 \mathrm{nM}$ with a detection limit of $300 \mathrm{pM}$. The sensor was demonstrated to be of general applicability by simply changing the signaling probe for molecular recognition. Yuan et al. used single-layer $\mathrm{MnO}_{2}$ nanoflakes decorated with dye-labeled ssDNA and peptides for the detection of ochratoxin A and cathepsin D, respectively [83]. The response to ochratoxin A was linear in the range of $0.02-2.0 \mathrm{ng} \mathrm{mL}^{-1}$ and was $>1000$ times larger than the response to its analogues aflatoxin B1 and B2. For cathepsin D detection a linear response was obtained for concentrations of $1-100 \mathrm{ng} \mathrm{mL}^{-1}$. Yang et al. used single-layer $\mathrm{MnO}_{2}$ nanoflakes decorated with dye-labeled DNA for the detection of microRNA inside living cells [91]. The $\mathrm{MnO}_{2}$ nanoflakes not only participated in the fluorescence signaling with a linear response between 0 and $100 \mathrm{pM}$ and a detection limit of $1 \mathrm{pM}$, but also facilitated cell internalization and protected the DNA label against enzymatic degradation. Dhenadhayalan et al. have reported the ultrasensitive detection of ssDNA with $\mathrm{MoO}_{3}$ nanoflakes for the application of prostate-specific antigen sensing in live cells [84]. A detection limit of $13 \mathrm{pM}$ was reached.

\subsubsection{Other sensors}

In vivo detection of ascorbic acid was demonstrated by Zhai et al. using single-layer $\mathrm{MnO}_{2}$ nanoflakes decorated with fluorescent 7-hydroxycoumarin [67]. The oxidation of ascorbic acid consumed the
$\mathrm{MnO}_{2}$ nanoflakes and thus restored the probe fluorescence. Though the oxidation is not selective towards ascorbic acid, the contribution of ascorbic acid was determined by reference measurements in which all ascorbic acid was removed by ascorbic acid oxidase. A linear response was obtained in the range of $0.5-40 \mu \mathrm{M}$ with a detection limit of $0.09 \mu \mathrm{M}$ and a sensitivity of $26 \mu \mathrm{M}^{-1}$. Hu et al. used $\mathrm{MnO}_{2}$ nanosheets for electrochemical oxidative sensing of $\mathrm{H}_{2} \mathrm{O}_{2}$ with a sensitivity of $3261 \mathrm{~mA} \mathrm{M}^{-1} \mathrm{~cm}^{-2}$ and linear responses between $25 \mathrm{nM}-2 \mu \mathrm{M}$ and $10-454 \mu \mathrm{M}$ [18]. The detection limit was $5 \mathrm{nM}$, which enabled detection of $\mathrm{H}_{2} \mathrm{O}_{2}$ released by living cells. The previously discussed fluorescent glucose sensor reported by Yuan et al. also detected $\mathrm{H}_{2} \mathrm{O}_{2}$, yielding a detection limit of $0.9 \mu \mathrm{M}$ and linear responses between 0 and $150 \mu \mathrm{M}$ and 180-350 $\mu \mathrm{M}$ [92].

Vabbina et al. have reported the electrochemical detection of cortisol with antibody-decorated $\mathrm{ZnO}$ nanoflakes, exploiting the favorable catalytic activity and charge transfer capability of the ZnO (0001) crystal plane [108]. This study is one of few that explicitly includes crystal facet engineering in sensor design. Yuan et al. have reported the electrochemical detection of $\mathrm{Hg}^{2+}$ cations via ion exchange with layered $\mathrm{Na}_{2} \mathrm{Ti}_{3} \mathrm{O}_{7}$ [99]. No interference was observed from $\mathrm{Cd}^{2+}$, $\mathrm{Mn}^{2+}, \mathrm{Ni}^{2+}, \mathrm{Pb}^{2+}$ and $\mathrm{Cu}^{2+}$ cations and the detection limit was as low as $0.005 \mathrm{ppb}(\sim 25 \mathrm{pM})$. Tan et al. have reported flowers of $\mathrm{MoO}_{3-\mathrm{x}}$ with an oxidized surface of $\mathrm{MoO}_{3}$ that were used for the detection of methylene blue via surface-enhanced Raman scattering (SERS) [98]. The plasmonic $\mathrm{MoO}_{3-\mathrm{x}}$ core electromagnetically increased the Raman scattering, while the non-plasmonic $\mathrm{MoO}_{3}$ shell prevented the photocatalytic degradation of the analyte. A detection limit of $0.1 \mu \mathrm{M}$ was reached, which is high for semiconductor SERS substrates, and the enhancement factor was comparable to values observed for noble metals, i.e. $1.42 \times 10^{5}$. How et al. have reported reduced graphene oxide (RGO) flakes that were decorated with (001)-faceted $\mathrm{TiO}_{2}$ nanoflakes for the electrochemical detection of dopamine [107]. This study is another example of sensor design based on crystal facet engineering; $\mathrm{TiO}_{2}(001)$ facets were created because of their higher surface energy and reactivity than $\mathrm{TiO}_{2}$ (101) facets [113,114]. A linear response was obtained between 2 and $60 \mu \mathrm{M}$ with a detection limit of $6 \mu \mathrm{M}$ [107].

\section{2D nanoflakes for gas sensing}

\subsection{Sensing mechanism}

Most metal oxide gas sensors are based on a chemiresistive sensing mechanism. In-depth descriptions of this sensing mechanism can be found elsewhere [115-117], but in short the electrical resistance of a metal oxide sensing unit is related to the ionosorption of oxidative species from the atmosphere on its surface. In oxygen-containing environments $\mathrm{O}_{2}$ adsorbs on the metal oxide as $\mathrm{O}_{2}{ }^{-}, \mathrm{O}^{-}$or $\mathrm{O}^{2-}$ and depletes electrons from the metal oxide surface region. This increases the electrical resistance in n-type semiconductor metal oxides and decreases the resistance in p-type semiconductors (hole accumulation). If the target species of a sensor is reducing such as $\mathrm{CO}, \mathrm{H}_{2}$ or various hydrocarbons, the gas molecules are oxidized by the anionic oxygen species at the metal oxide surface and the resulting electrons are injected back into the metal oxide lattice. This again changes the charge carrier density and thus the electrical resistivity of the sensing unit. Operation temperatures of $100-500{ }^{\circ} \mathrm{C}$ are generally required to achieve sufficient ionosorption and activation of $\mathrm{O}_{2}$. If the target species of a sensor is itself oxidative, such as $\mathrm{NO}_{2}$, no intermediate adsorbents are required and ionosorption of $\mathrm{NO}_{2}$ directly affects the metal oxide resistivity. Sensing of oxidative species favors lower operation temperatures to suppress competitive $\mathrm{O}_{2}$ ionosorption. As alternative to this oxygen ionosorption model, chemiresistive sensing can also be described by an oxygen vacancy model $[117,118]$. This model focuses on changes in the oxygen stoichiometry as a result of reactions between oxygen vacancies and gas molecules. Chemiresistive sensors are not intrinsically selective towards specific target molecules; the electronic 
properties of the metal oxide sensing element can be affected by any oxidizing or reducing species and even by merely physisorbed molecules [119].

\subsection{Materials}

In general, n-type semiconductors provide higher gas responses than p-type semiconductors because of the difference in localization of conductive and resistive regions [115,117]. The ionosorption of oxidative species withdraws electrons from the metal oxide surface and thus creates a resistive electron-depleted shell around the semiconducting core for n-type semiconductors. An applied current will travel primarily through the less resistive core of the particle, but needs to cross a resistive barrier when travelling from one particle to another. This barrier height is sensitive to the number of ionosorbed oxidative species on the metal oxide surface. The sensor sensitivity increases dramatically with the $2 \mathrm{D}$ thickness decreasing to below twice the thickness of the electron depletion layer, i.e. with the electrical resistivity of the metal oxide becoming fully surface-dependent. The depletion layer thickness varies with the charge carrier density, band bending and relative permittivity of the metal oxide [120]. For p-type semiconductors the ionosorption of oxidative species creates a conductive hole-accumulated shell around the semiconducting core. Now the applied current will travel primarily along the conductive shell of the particle and is still affected by the amount of ionosorbed surface species, but to a lesser extent than for n-type materials. Also the 2D thickness and the number of interparticle contacts have less influence on the sensitivity of p-type materials. For identical morphologies the response of p-type materials only equals the square root of that of ntype materials [121]. Advantages of p-type materials tend to be their stronger affinity for oxygen, higher catalytic activity and reduced humidity dependence $[115,122]$.

Electronic processes vary significantly with minor changes in chemical composition, stoichiometry and crystal quality. It is generally believed that oxygen vacancies facilitate the formation of oxygen species on the crystal surface and/or offer active sites for gas adsorption [117]. Metal cation defects are important especially in p-type semiconductors, but studies on their role are rare [117,123]. For 2D NiO sensors the sensitivity towards $\mathrm{NO}_{2}$ has been reported to increase with increasing nickel vacancy concentrations [123]. Although the majority of 2D metal oxide sensors contains only one metal species, multicomponent structures can be obtained via internal doping, external decoration or composite formation. Secondary components can improve the sensor performance e.g. by changing the charge carrier concentration (electronic sensitization) [124], creating $p$ - $n$ junctions [125-127] and catalyzing chemical interactions [20] or increasing the adsorbed gas concentration via the spillover effect [128] (chemical sensitization). More information on the physics of multicomponent structures can be found in a review on nanoscale metal oxide-based heterojunctions for gas sensing by Miller et al. [129].

Despite increasing insight, the rational design of gas sensing materials is still hindered by the lack of detailed knowledge on the relation between intrinsic material properties, processing details and their performance. This issue was recently discussed by Zhang et al. in a review on metal oxide semiconductors for gas sensing, sketching the tremendous number of possibilities in material engineering and highlighting efforts on high-throughput material screening for sensor applications [117]. Rational design is especially difficult with respect to the selectivity of chemiresistive gas sensors, which hinders widespread application for the detection of low-concentration and low-reactive targets such as indoor air pollutants (e.g. benzene, xylene, toluene) and breath biomarkers (e.g. $\mathrm{H}_{2} \mathrm{~S}, \mathrm{CO}$, acetone, $\mathrm{NH}_{3}$ and NO) [130]. Various examples of suitable catalyst-target gas combinations are given in a review by Woo et al. [130].

An overview of literature reports on 2D metal oxide nanoflakes that have served as active gas sensing element is given in Table 4, listing the used metal oxides, architectures, syntheses, nanoflake thicknesses and molecules towards which the sensing performance was tested. The differentiation between various metal oxides is schematically shown in Fig. 6; the most widely used metal oxides are $\mathrm{ZnO}, \mathrm{SnO}_{2}, \mathrm{NiO}, \mathrm{WO}_{3}$ and $\mathrm{In}_{2} \mathrm{O}_{3}$. All of these materials have a wide band gap, which is beneficial for reducing background signals due to thermally activated conduction. Other advantages include the high dopability of $\operatorname{In}_{2} \mathrm{O}_{3}$ [20], the low cost and high chemical and thermal stability of $\mathrm{SnO}_{2}$ [131] and the large exciton binding energy of $\mathrm{ZnO}[132,133]$. Less commonly used metal oxides include $\mathrm{Co}_{3} \mathrm{O}_{4}, \mathrm{MoO}_{3}, \mathrm{CuO}, \mathrm{Fe}_{2} \mathrm{O}_{3}, \mathrm{Bi}_{2} \mathrm{WO}_{6}, \mathrm{MnO}_{2}, \mathrm{~V}_{2} \mathrm{O}_{5}$, $\mathrm{Cu}_{2} \mathrm{O}, \mathrm{RuO}_{2}, \mathrm{Sn}_{3} \mathrm{O}_{4}, \mathrm{TiO}_{2}, \mathrm{~V}_{4} \mathrm{O}_{9}, \mathrm{ZnFe}_{2} \mathrm{O}_{4}, \mathrm{ZnSnO}_{3}$ and layered double hydroxides of $\mathrm{Mg}-\mathrm{Al}$ and $\mathrm{Ni}-\mathrm{Fe}-\mathrm{Al}$.

\subsection{Performance}

Among the various types of $2 \mathrm{D}$ metal oxide gas sensors, the ones with predominant responses towards $\mathrm{NO}_{2}$, acetone, ethanol and formaldehyde have been reported most. For each of these gases an overview of reported maximum sensor responses at concentrations up to 200 ppm is given in Fig. 7, together with an indication of which materials are used most (based on the number of publications). Table 5 lists the details of 2D metal oxide sensors with the highest responses for a variety of other target gases. Because of the intrinsically unselective nature of the chemiresistive sensing mechanism (see Section 4.1), many approaches to increase the sensor response towards either $\mathrm{NO}_{2}$ or acetone, ethanol and formaldehyde will have a qualitatively similar effect on the sensor response towards other oxidizing or reducing target gases, respectively. In this review, the response of gas sensors is defined as the resistance ratio $R_{\mathrm{air}} / R_{\mathrm{gas}}$ or $R_{\mathrm{gas}} / R_{\text {air }}$, depending on the metal oxide (p-type or n-type) and target species (oxidizing or reducing). Literature values based on different definitions were converted to facilitate comparison. Occasionally, reported data is based on a reference atmosphere of $\mathrm{N}_{2}$ instead of air.

\subsection{1. $\mathrm{NO}_{2}$ sensors}

For $\mathrm{NO}_{2}$ detection the highest responses have been reached with $\mathrm{In}_{2} \mathrm{O}_{3}$ as $2 \mathrm{D}$ sensing materials. $\mathrm{Hu}$ et al. have reported $\mathrm{In}_{2} \mathrm{O}_{3}$ flower architectures that were decorated with PdO particles and reached responses of up to 4080 for $50 \mathrm{ppm} \mathrm{NO}_{2}$ at the optimal operation temperature of $110{ }^{\circ} \mathrm{C}$ [20]. The response towards $\mathrm{NO}_{2}$ was approximately 2500-4000 times larger than that towards $\mathrm{CH}_{4}, \mathrm{H}_{2}$, $\mathrm{CO}$ and ethanol and gas concentrations down to $500 \mathrm{ppb}$ could be detected. This excellent performance is explained by the catalyzing effect of $\mathrm{Pd}$, which activates the dissociation of both environmental $\mathrm{O}_{2}$ and targeted $\mathrm{NO}_{2}$ on the sensor surface. This causes electron depletion in $\operatorname{In}_{2} \mathrm{O}_{3}$ and thereby increases its electrical resistance. The undoped $\operatorname{In}_{2} \mathrm{O}_{3}$ sensor reached a maximum $\mathrm{NO}_{2}$ response of 1310 for $50 \mathrm{ppm}$, which is still very high as compared to the other metal oxides (see Fig. 7). Another high-performance gas sensor for $\mathrm{NO}_{2}$ detection has been reported by Liu et al. based on $\operatorname{In}_{2} \mathrm{O}_{3}$ flower architectures decorated with reduced graphene oxide sheets to create local $p$ - $n$ junctions [125]. The highest response was 1337 for $1 \mathrm{ppm} \mathrm{NO} \mathrm{Na}_{2}$ at $74^{\circ} \mathrm{C}$ and the $\mathrm{NO}_{2}$ response was $20-1000^{+}$ larger than the response towards $\mathrm{NH}_{3}, \mathrm{H}_{2} \mathrm{~S}, \mathrm{O}_{3}, \mathrm{SO}_{2}, \mathrm{Cl}_{2}$, ethanol and acetone. $\mathrm{NO}_{2}$ detection was achieved down to a concentration of $10 \mathrm{ppb}$ and room temperature responses of up to 1098 were reached for $1 \mathrm{ppm}$. $\mathrm{Xu}$ et al. have reported pure $\mathrm{In}_{2} \mathrm{O}_{3}$ flowers with porous petals that reached a room temperature response of 1210 for $1 \mathrm{ppm} \mathrm{NO}_{2}$ with $30 \%$ relative humidity and could detect concentrations down to $50 \mathrm{ppb}$ [156]. $\mathrm{NO}_{2}$ sensors based on $\mathrm{WO}_{3}$ flower architectures have been reported by Wang et al., reaching responses of 150-250 for $0.8 \mathrm{ppm} \mathrm{NO}_{2}$ at $90-120^{\circ} \mathrm{C}$ while being able to detect concentrations down to 2-40 ppb [216,217].

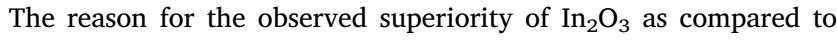
other metal oxides for $\mathrm{NO}_{2}$ detection is unclear. Hu et al. have proposed the high electrical conductance of $\operatorname{In}_{2} \mathrm{O}_{3}$ as reason for its popularity in gas sensor development [20]. However, the charge carrier 


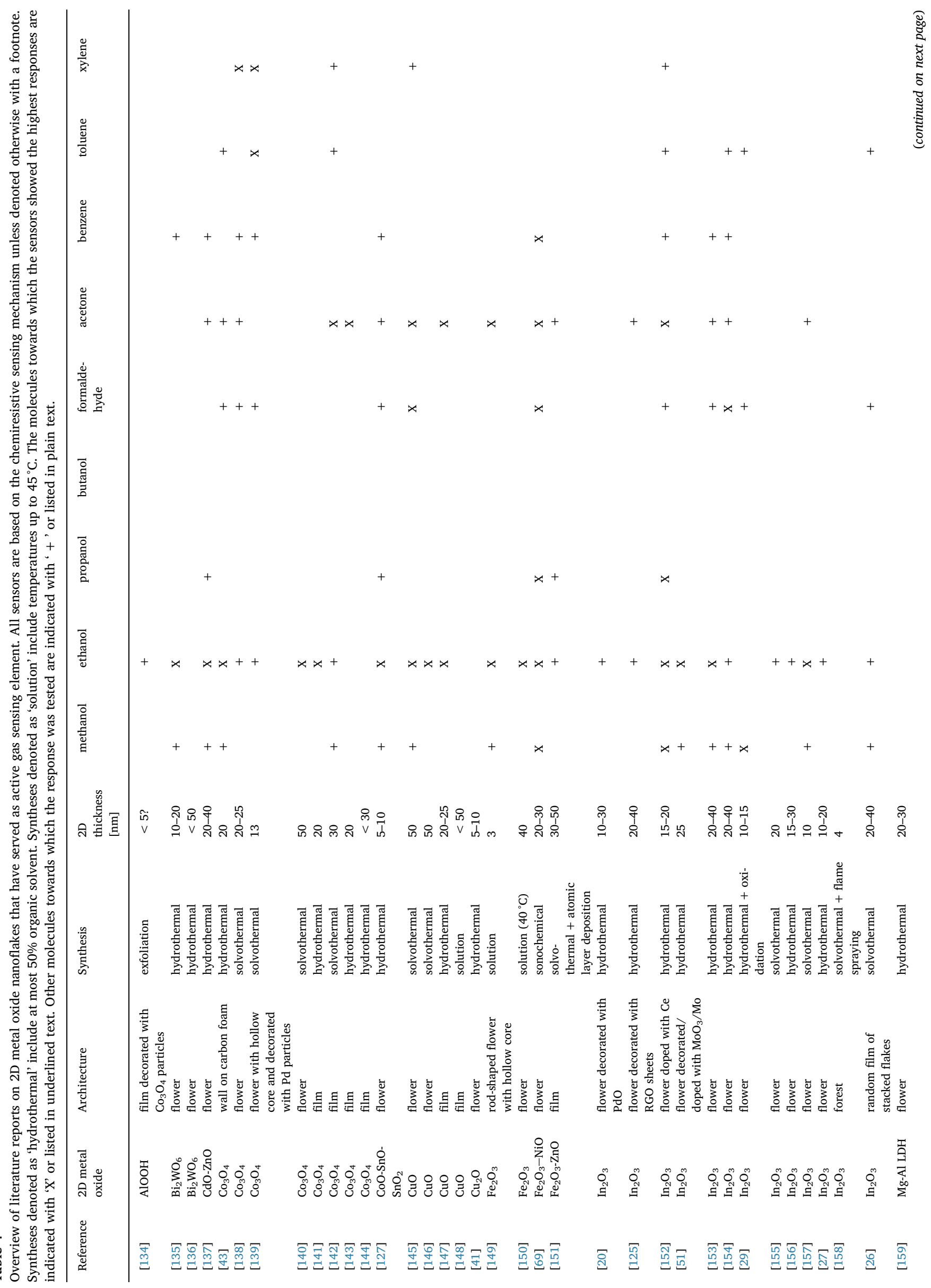




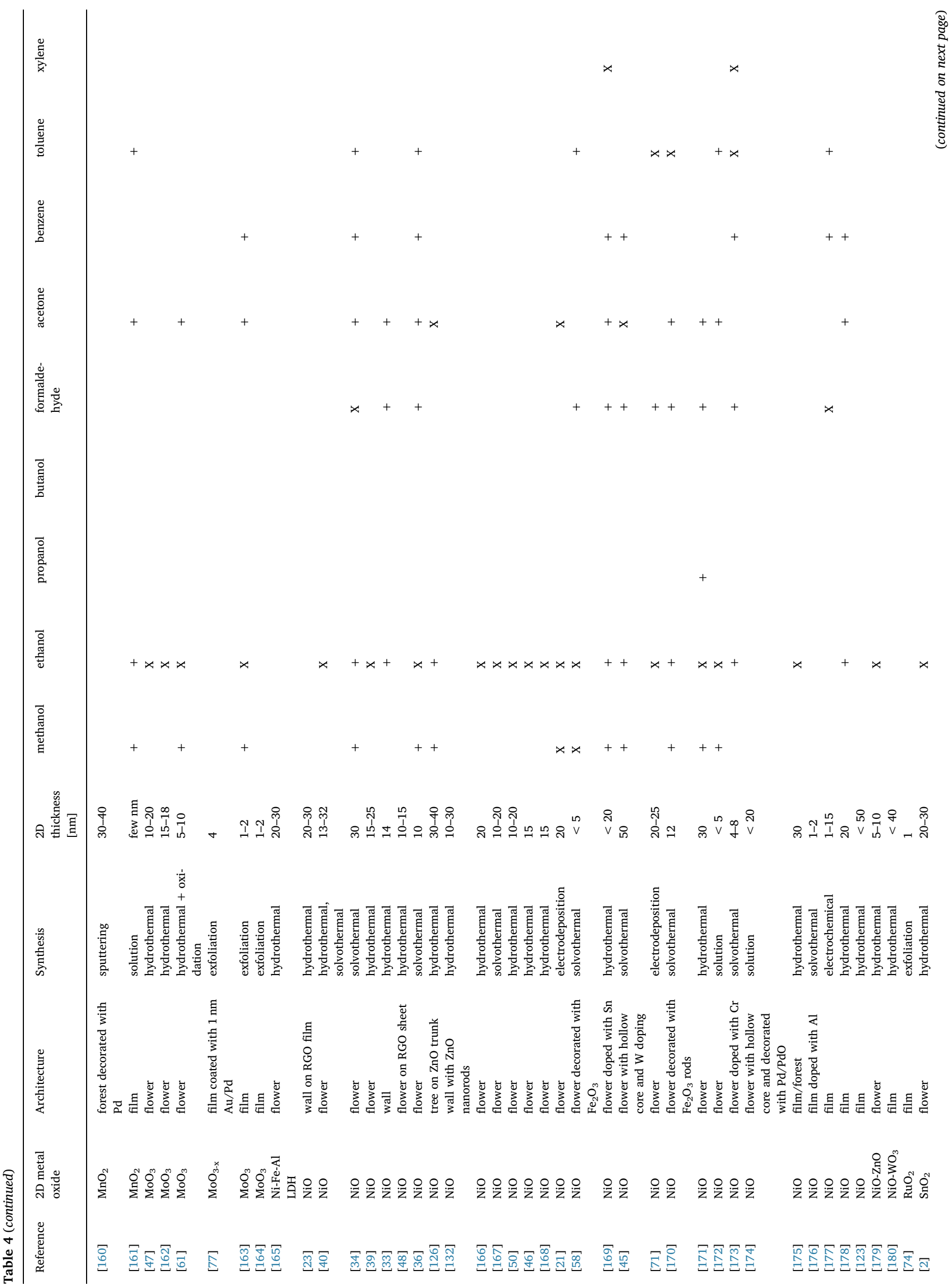




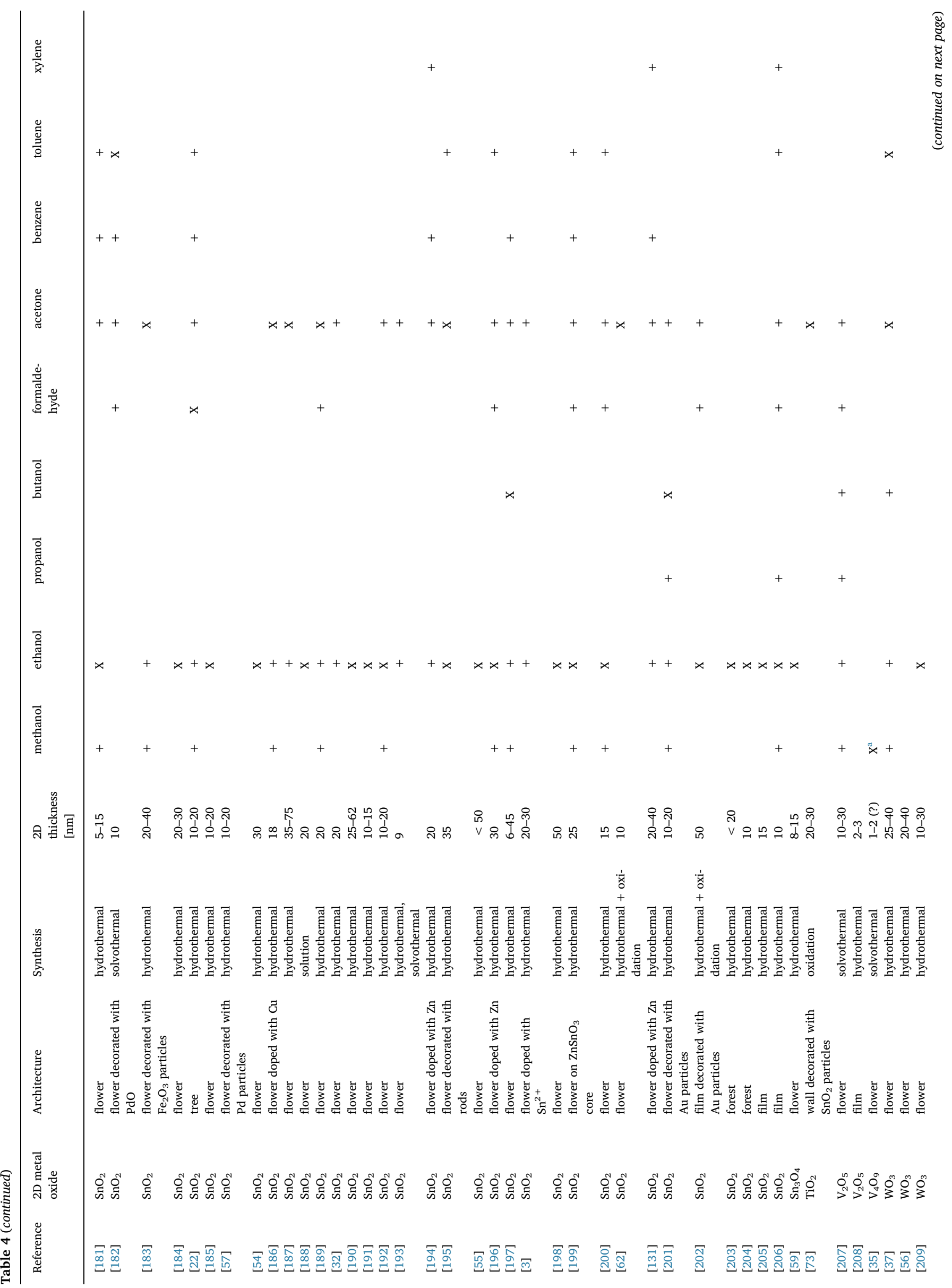




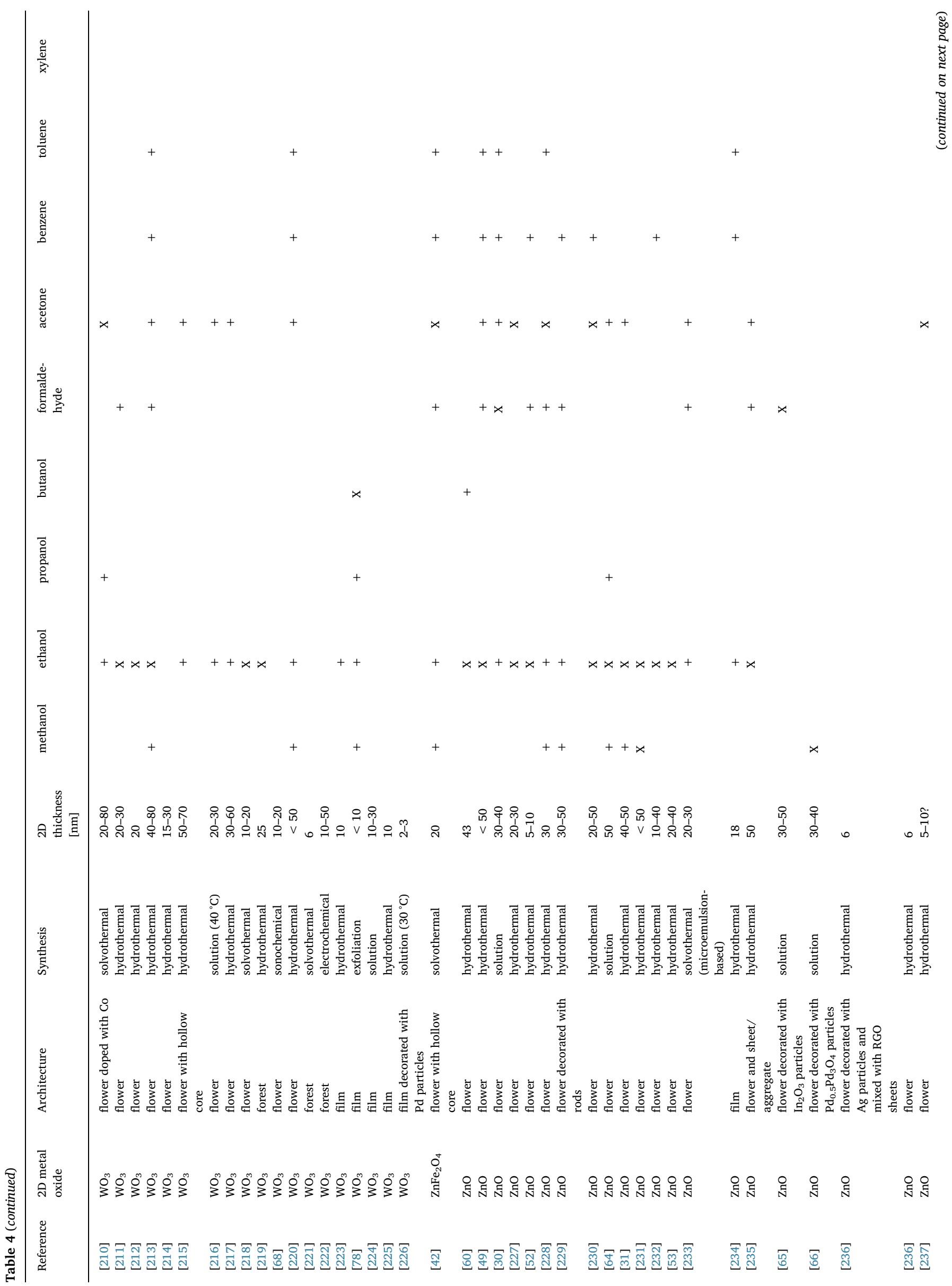




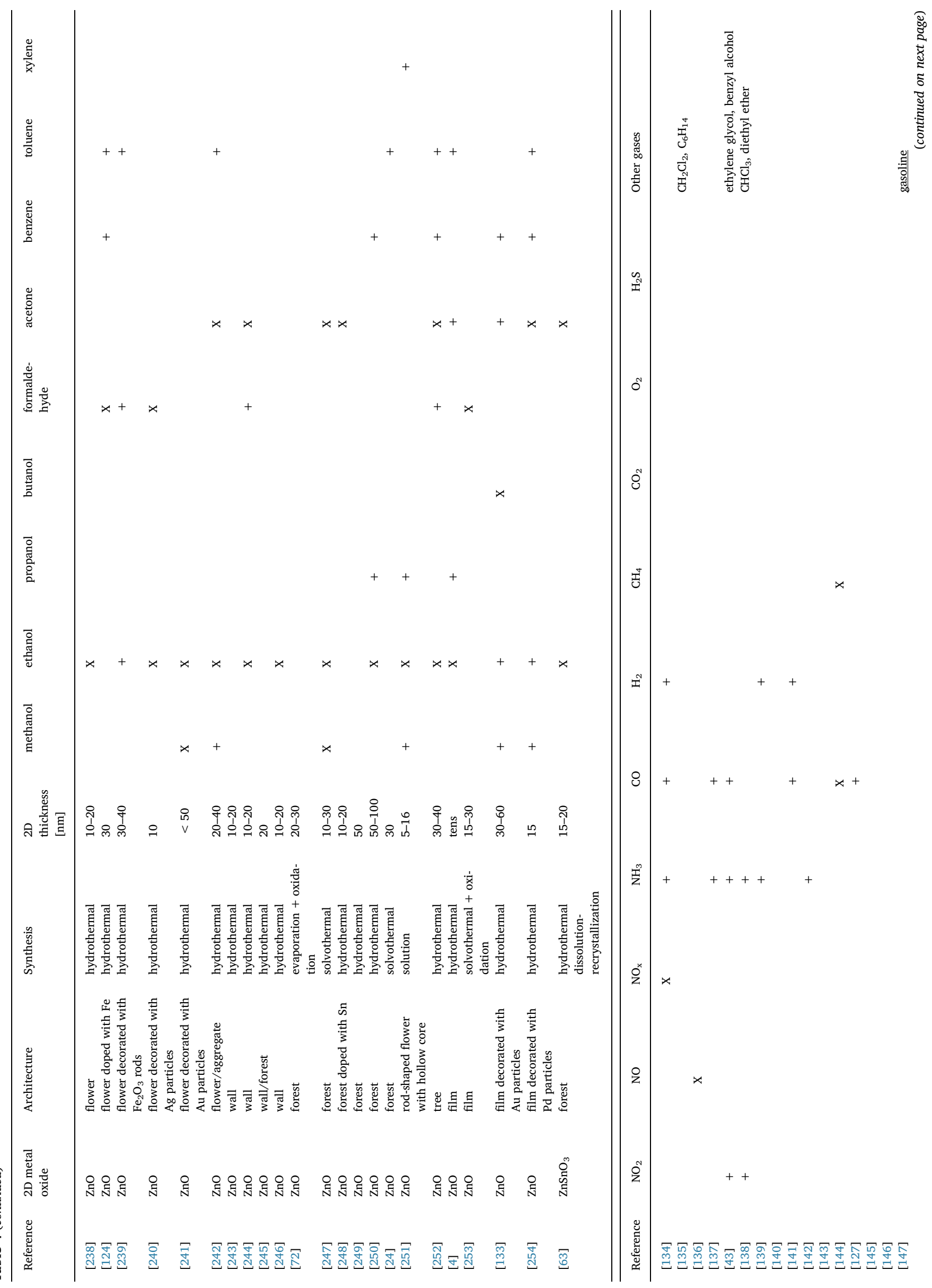




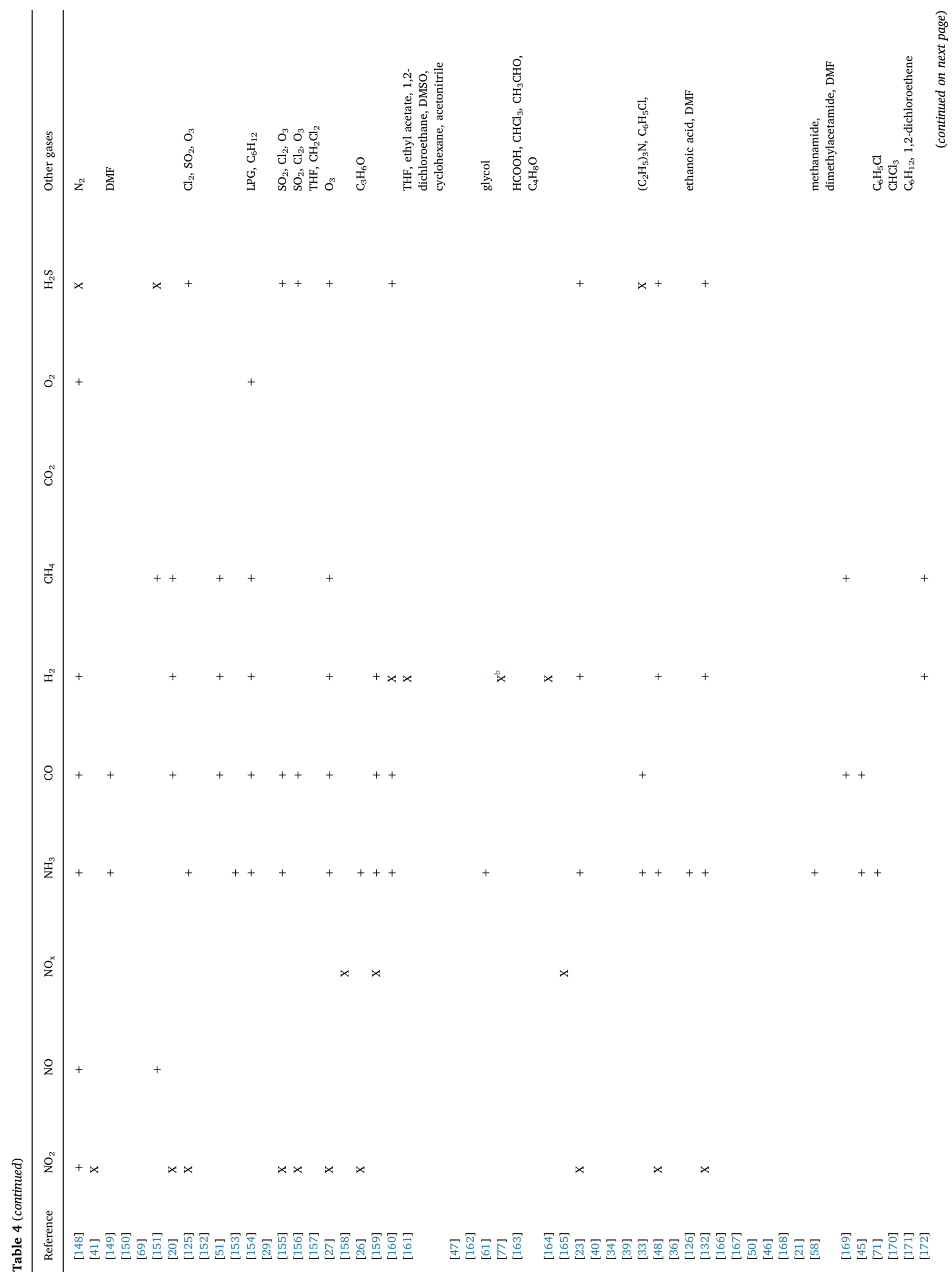




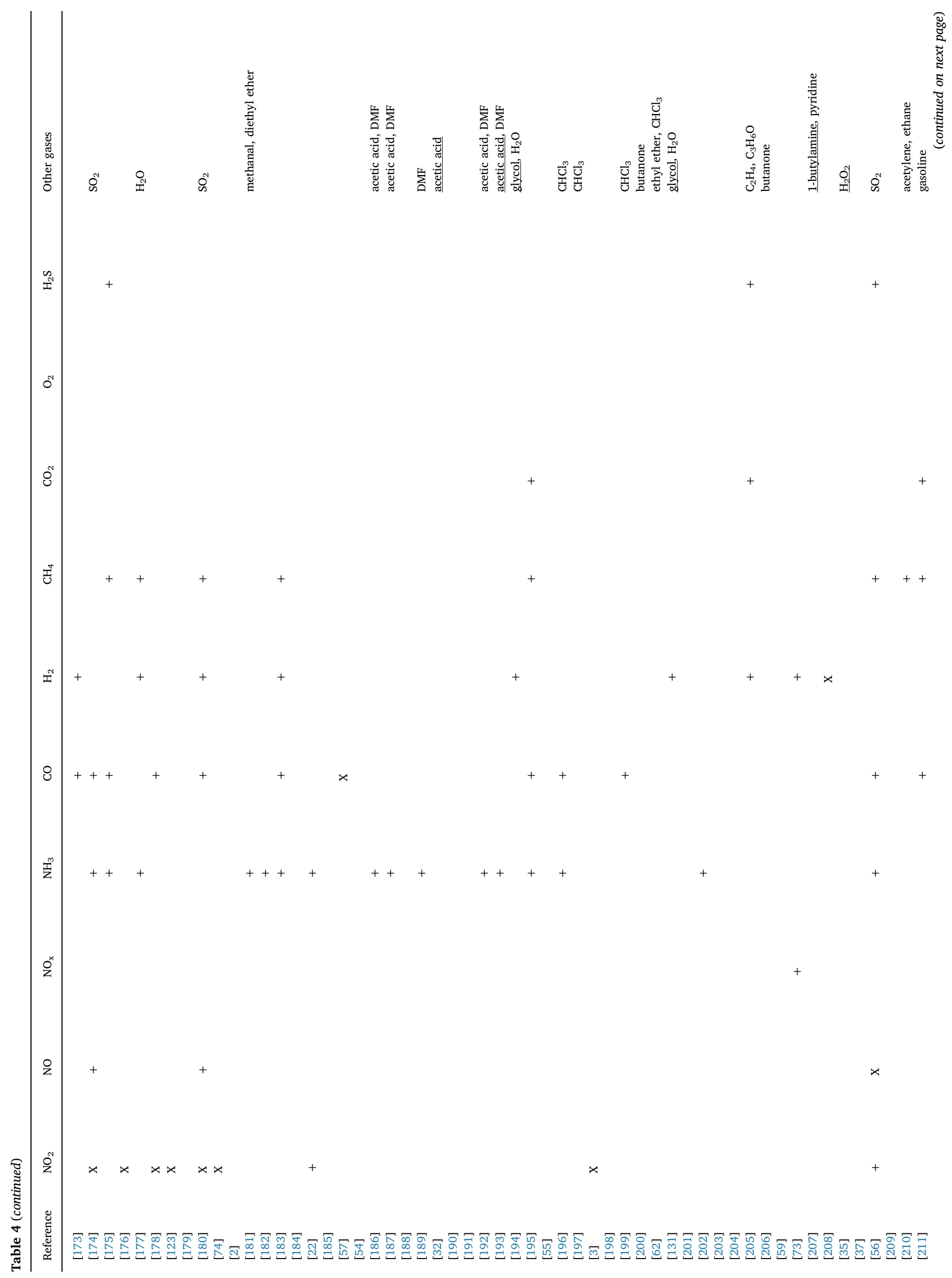




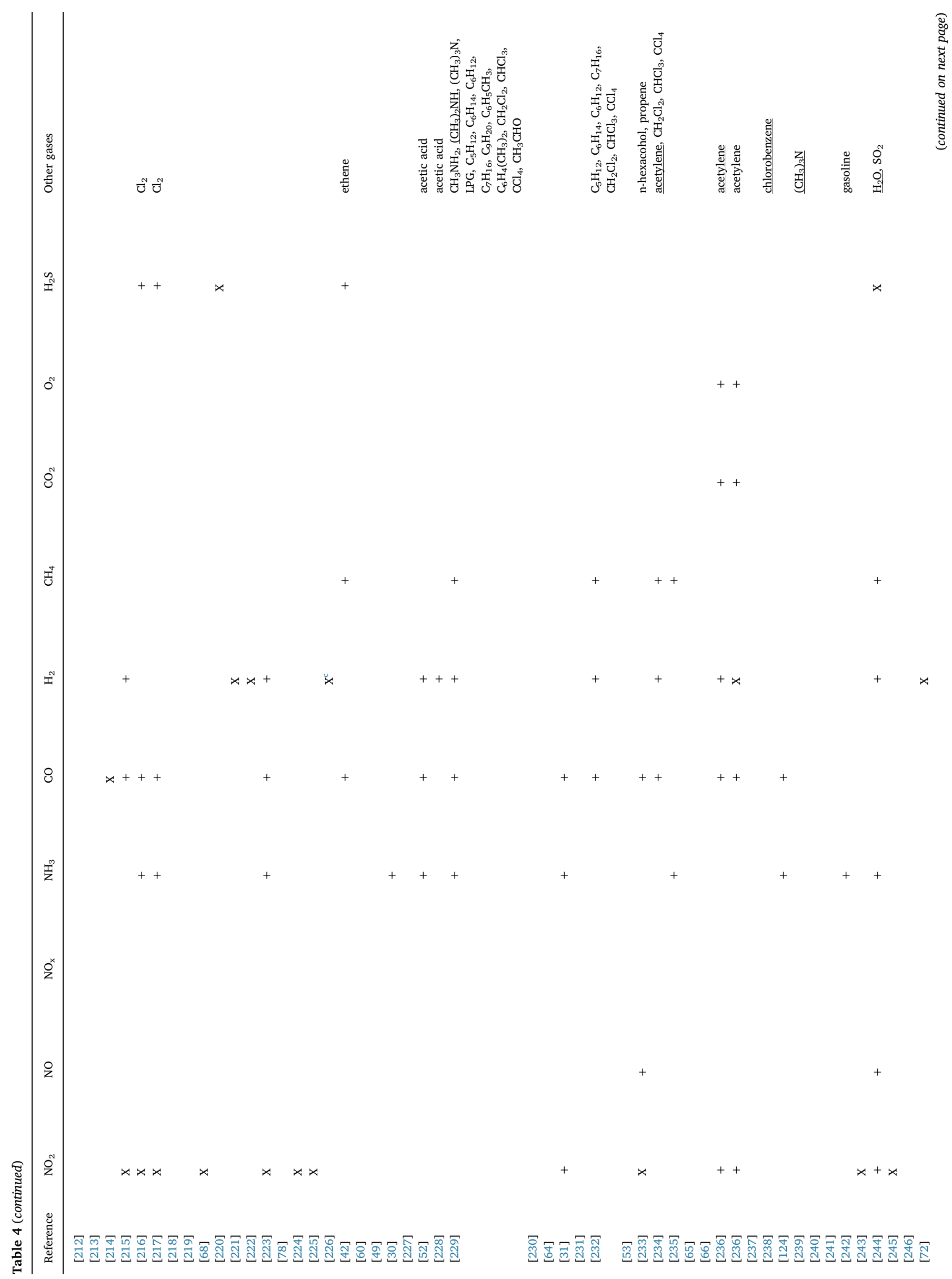



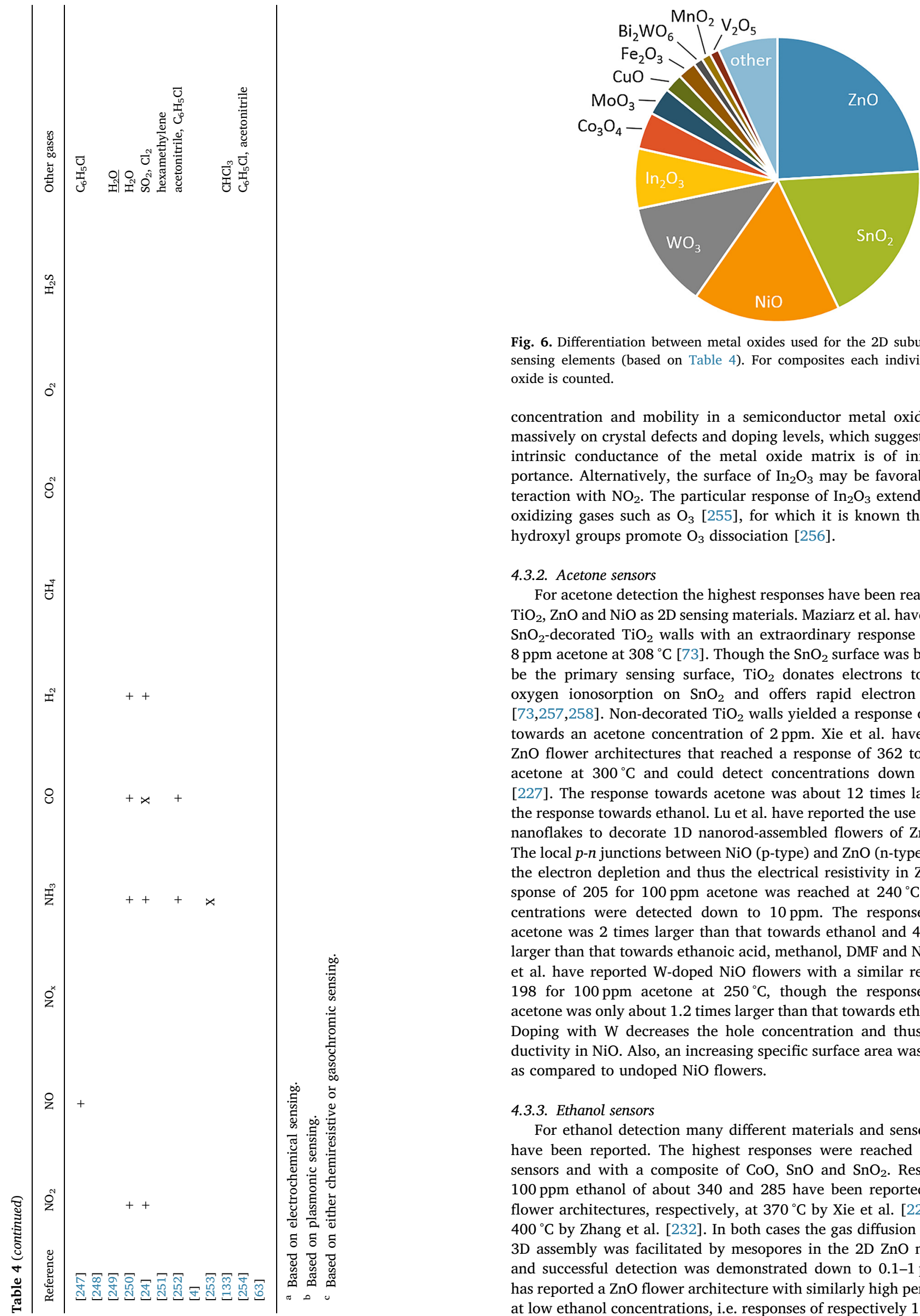

Fig. 6. Differentiation between metal oxides used for the 2D subunits in gas sensing elements (based on Table 4). For composites each individual metal oxide is counted.

concentration and mobility in a semiconductor metal oxide depend massively on crystal defects and doping levels, which suggests that the intrinsic conductance of the metal oxide matrix is of inferior importance. Alternatively, the surface of $\mathrm{In}_{2} \mathrm{O}_{3}$ may be favorable for interaction with $\mathrm{NO}_{2}$. The particular response of $\operatorname{In}_{2} \mathrm{O}_{3}$ extends to other oxidizing gases such as $\mathrm{O}_{3}$ [255], for which it is known that surface hydroxyl groups promote $\mathrm{O}_{3}$ dissociation [256].

\subsubsection{Acetone sensors}

For acetone detection the highest responses have been reached with $\mathrm{TiO}_{2}, \mathrm{ZnO}$ and $\mathrm{NiO}$ as $2 \mathrm{D}$ sensing materials. Maziarz et al. have reported $\mathrm{SnO}_{2}$-decorated $\mathrm{TiO}_{2}$ walls with an extraordinary response of 348 to $8 \mathrm{ppm}$ acetone at $308^{\circ} \mathrm{C}$ [73]. Though the $\mathrm{SnO}_{2}$ surface was believed to be the primary sensing surface, $\mathrm{TiO}_{2}$ donates electrons to increase oxygen ionosorption on $\mathrm{SnO}_{2}$ and offers rapid electron transport $[73,257,258]$. Non-decorated $\mathrm{TiO}_{2}$ walls yielded a response of about 2 towards an acetone concentration of $2 \mathrm{ppm}$. Xie et al. have reported $\mathrm{ZnO}$ flower architectures that reached a response of 362 to $100 \mathrm{ppm}$ acetone at $300^{\circ} \mathrm{C}$ and could detect concentrations down to $1 \mathrm{ppm}$ [227]. The response towards acetone was about 12 times larger than the response towards ethanol. Lu et al. have reported the use of $2 \mathrm{D} \mathrm{NiO}$ nanoflakes to decorate 1D nanorod-assembled flowers of ZnO [126]. The local $p$ - $n$ junctions between $\mathrm{NiO}$ (p-type) and $\mathrm{ZnO}$ (n-type) increase the electron depletion and thus the electrical resistivity in $\mathrm{ZnO}$. A response of 205 for $100 \mathrm{ppm}$ acetone was reached at $240{ }^{\circ} \mathrm{C}$ and concentrations were detected down to $10 \mathrm{ppm}$. The response towards acetone was 2 times larger than that towards ethanol and 4-15 times larger than that towards ethanoic acid, methanol, $\mathrm{DMF}$ and $\mathrm{NH}_{3}$. Wang et al. have reported $\mathrm{W}$-doped $\mathrm{NiO}$ flowers with a similar response of 198 for $100 \mathrm{ppm}$ acetone at $250^{\circ} \mathrm{C}$, though the response towards acetone was only about 1.2 times larger than that towards ethanol [45]. Doping with $\mathrm{W}$ decreases the hole concentration and thus the conductivity in NiO. Also, an increasing specific surface area was observed as compared to undoped $\mathrm{NiO}$ flowers.

\subsubsection{Ethanol sensors}

For ethanol detection many different materials and sensor designs have been reported. The highest responses were reached with $\mathrm{ZnO}$ sensors and with a composite of $\mathrm{CoO}, \mathrm{SnO}$ and $\mathrm{SnO}_{2}$. Responses to $100 \mathrm{ppm}$ ethanol of about 340 and 285 have been reported for $\mathrm{ZnO}$ flower architectures, respectively, at $370^{\circ} \mathrm{C}$ by Xie et al. [227] and at $400{ }^{\circ} \mathrm{C}$ by Zhang et al. [232]. In both cases the gas diffusion inside the $3 \mathrm{D}$ assembly was facilitated by mesopores in the $2 \mathrm{D} \mathrm{ZnO}$ nanoflakes and successful detection was demonstrated down to $0.1-1 \mathrm{ppm}$. Guo has reported a $\mathrm{ZnO}$ flower architecture with similarly high performance at low ethanol concentrations, i.e. responses of respectively 17 and 112 

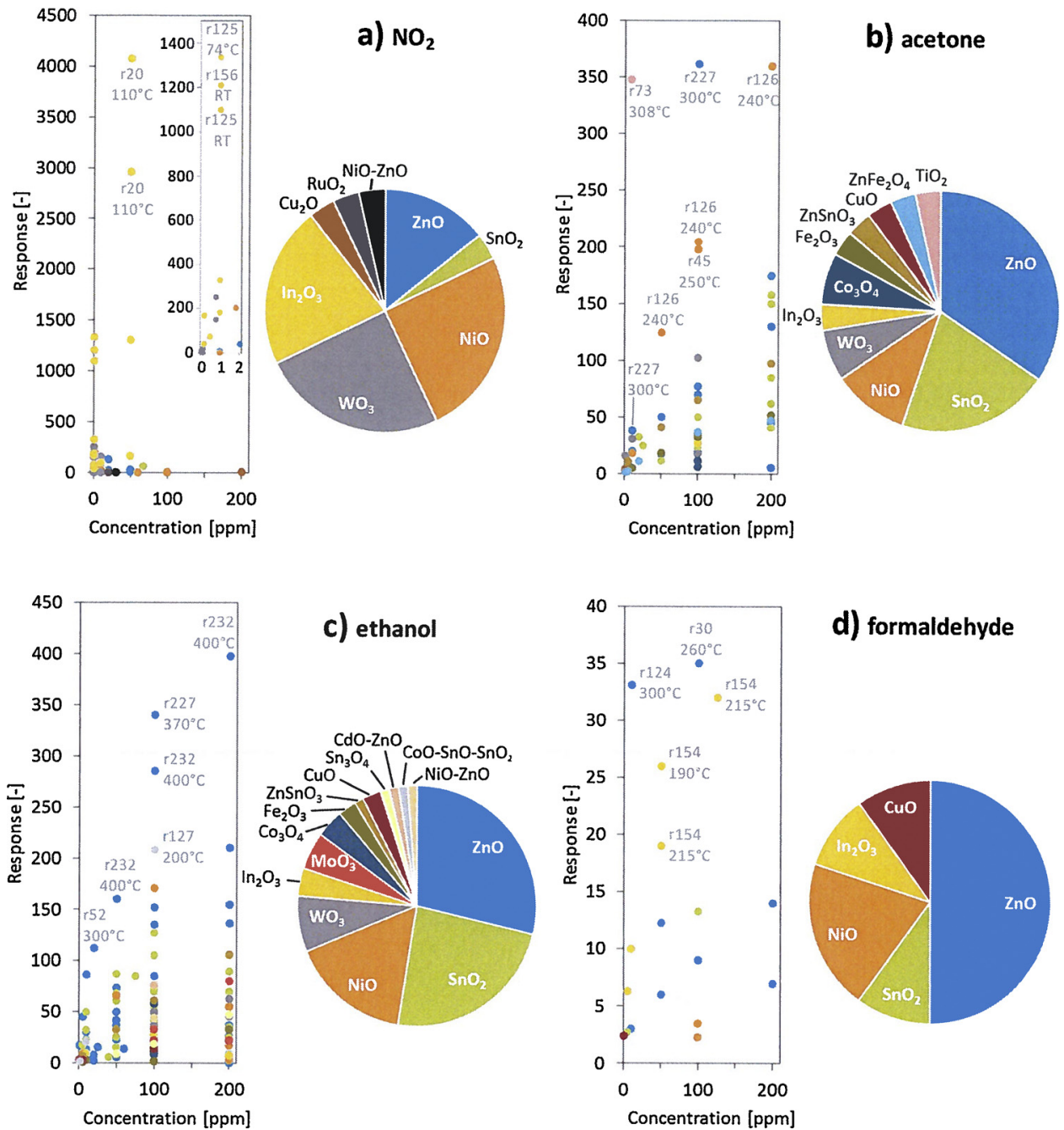

Fig. 7. Overview of reported maximum responses and used materials (based on the number of publications) for $2 \mathrm{D}$ metal oxide gas sensors for (a) $\mathrm{NO}_{2}$ detection with the inset zooming in on low concentrations, (b) acetone detection, (c) ethanol detection and (d) formaldehyde detection. All sensors from Table 4 with selective behavior towards $\mathrm{NO}_{2}$, acetone, ethanol and/or formaldehyde are included except [39,69,135,147,185,199].

for 1 and $20 \mathrm{ppm}$ at $300{ }^{\circ} \mathrm{C}$, but for higher concentrations its response leveled off at about 130 [52]. Wang et al. have reported a flower architecture of a composite of $\mathrm{CoO}, \mathrm{SnO}$ and $\mathrm{SnO}_{2}$ [127]. The many $p$ - $n$ junctions between $\mathrm{CoO}$ (p-type) and $\mathrm{SnO}_{2}$ (n-type) yield depletion of charge carriers and thus an increasing resistance in the sensing body. Also, $\mathrm{CoO}$ was believed to catalyze the dissociation of ethanol molecules on the sensor surface. A Co:Sn ratio of 1 yielded a response of 208 to $100 \mathrm{ppm}$ ethanol, which is lower than the responses of $\mathrm{ZnO}$ flowers mentioned above, but an important advantage of the $\mathrm{Co} / \mathrm{Sn}$ oxide sensor is its significantly lower sensing temperature of $200{ }^{\circ} \mathrm{C}$. Roomtemperature ethanol sensing has been reported by Alenezi et al. using $\mathrm{ZnO}$ nanodisks that were activated with UV irradiation [4]. Though UV irradiation decreases the overall amount of oxygen adsorbed on the sensor surface, the presence of excitons promotes oxygen adsorption in the more active atomic form $\left(\mathrm{O}^{-}\right)$rather than the less active molecular form $\left(\mathrm{O}_{2}{ }^{-}\right)$. A response of about 1.3 was reached for $200 \mathrm{ppm}$ ethanol under $1.6 \mathrm{~mW} \mathrm{~cm}^{-2} \mathrm{UV}$ irradiation.

\subsubsection{Formaldehyde sensors}

Formaldehyde detection has been reported with the highest responses for $\mathrm{ZnO}$ and $\mathrm{In}_{2} \mathrm{O}_{3}$ sensors. Cao et al. reached a response of 35 for $100 \mathrm{ppm}$ formaldehyde at $260^{\circ} \mathrm{C}$ with a $\mathrm{ZnO}$ flower architecture [30]. The response towards formaldehyde was 2.3 times larger than the response towards ethanol, 4 times larger than the response towards acetone and $>10$ times larger than the response towards $\mathrm{NH}_{3}$, toluene and benzene. ZnO flowers with Fe doping have been reported by Guo, yielding a response of 33 for a formaldehyde concentration of only $10 \mathrm{ppm}$ at $300{ }^{\circ} \mathrm{C}$ [124]. Substituting $\mathrm{Zn}^{2+}$ in the $\mathrm{ZnO}$ lattice with $\mathrm{Fe}^{3+}$ causes the release of more electrons in the conduction band. This facilitates the reduction of $\mathrm{O}_{2}$ at the sensor surface and thereby increases the number of sites where formaldehyde can be oxidized. Also, Fe doping is believed to enhance gas sensing via increasing the oxygen vacancy concentration. Zhang et al. have reported $\operatorname{In}_{2} \mathrm{O}_{3}$ flowers with mesoporous petals that detected $50 \mathrm{ppm}$ formaldehyde at $190^{\circ} \mathrm{C}$ with a response of 26 [154]. At $215^{\circ} \mathrm{C}$ the responses were 19 for $50 \mathrm{ppm}$ and 32 for $125 \mathrm{ppm}$.

\subsubsection{Comparison}

When considering the performance of various metal oxides with respect to the number of literature reports (see Fig. 3), $\operatorname{In}_{2} \mathrm{O}_{3}$ has yielded several of the sensors with the highest responses while it represents only $7 \%$ of the gas sensor reports included in this review. In terms of sensitivity (note that speed and stability of the sensors are not considered in the present review) $\mathrm{In}_{2} \mathrm{O}_{3}$ thus appears promising for further development in 2D-based sensing elements, though the precise reason for its success remains unclear (see Section 4.3.1). ZnO has been used for many of the most responding as well as least responding gas sensors, indicating no intrinsic superiority of $\mathrm{ZnO}$ as compared to the other metal oxides. As for $\mathrm{SnO}_{2}$, it has been used in about $20 \%$ of the literature reports on gas sensors included in this review and has been 
Table 5

Details of 2D metal oxide sensors with the highest responses for various target gases.

\begin{tabular}{|c|c|c|c|c|c|}
\hline Target species & Concentration [ppm] & Response & Temperature $\left[{ }^{\circ} \mathrm{C}\right]$ & 2D metal oxide & Reference \\
\hline methanol & $1 / 5$ & $2.7 / 8.4$ & 230 & $\mathrm{NiO}$ (flower) & [21] \\
\hline methanol & $20 / 100$ & $30 / 108$ & 255 & $\mathrm{NiO}$ (flower, porous petals, $\mathrm{Fe}_{2} \mathrm{O}_{3}$-decorated) & {$[58]$} \\
\hline butanol & $2 / 100$ & $31 / 161$ & 300 & $\mathrm{WO}_{3}$ (film) & [78] \\
\hline toluene & 5 & 305 & 250 & $\mathrm{Co}_{3} \mathrm{O}_{4}$ (hollow flower, Pd-decorated) & [139] \\
\hline xylene & 5 & 361 & 250 & $\mathrm{Co}_{3} \mathrm{O}_{4}$ (hollow flower, Pd-decorated) & [139] \\
\hline xylene & 5 & 164 & 250 & $\mathrm{Co}_{3} \mathrm{O}_{4}$ (hollow flower) & [139] \\
\hline chlorobenzene & 100 & 6.9 & 200 & $\mathrm{ZnO}$ (flower, porous petals) & [238] \\
\hline acetic acid & $50 / 100 / 200$ & $15 / 132 / 351$ & 340 & $\mathrm{SnO}_{2}$ (flower, porous petals) & {$[32]$} \\
\hline acetylene & $1 / 200 / 1 / 200$ & $10 / 164 / 4 / 22$ & $400 / 400 / 285 / 285$ & $\mathrm{ZnO}$ (aggregated film, porous flakes) & [234] \\
\hline acetylene & 100 & 12.3 & 200 & ZnO (flower, Ag- and RGO-decorated) & {$[236]$} \\
\hline dimethylamine & $1 / 200$ & $16.8 / 2087$ & 370 & ZnO (flower, porous petals, rod-decorated) & [229] \\
\hline trimethylamine & $20 / 200$ & $3.9 / 11.6$ & 260 & $\mathrm{ZnO}$ (flower, $\mathrm{Fe}_{2} \mathrm{O}_{3}$-decorated) & [239] \\
\hline glycol & $5 / 100$ & $5 / 90$ & 240 & $\mathrm{SnO}_{2}$ (flower, $\mathrm{Zn}$-doped) & [194] \\
\hline $\mathrm{CO}$ & $10 / 40$ & $>25 />100$ & RT & $\mathrm{Co}_{3} \mathrm{O}_{4}$ (aggregated film, porous flakes) & [144] \\
\hline $\mathrm{CH}_{4}$ & $10 / 40$ & $>25 />100$ & RT & $\mathrm{Co}_{3} \mathrm{O}_{4}$ (aggregated film, porous flakes) & {$[144]$} \\
\hline $\mathrm{H}_{2}$ & 100 & 15 & 200 & $\mathrm{ZnO}$ (flower) & [236] \\
\hline $\mathrm{H}_{2}$ & 100 & $3.3 / 11.4 / 20.5$ & $25 / 100 / 300$ & $\mathrm{MnO}_{2}$ (forest, Pd-decorated) & {$[160]$} \\
\hline $\mathrm{H}_{2} \mathrm{~S}$ & $2.5 / 50$ & $164 / 2185$ & 200 & $\mathrm{ZnO}$ (wall, porous) & [244] \\
\hline $\mathrm{H}_{2} \mathrm{O}$ & $50 \% / 90 \% \mathrm{RH}$ & $9 / 345$ & 25 & $\mathrm{ZnO}$ (wall, porous) & {$[244]$} \\
\hline $\mathrm{H}_{2} \mathrm{O}$ & 60 & 2 & RT & $\mathrm{ZnO}$ (forest) & [249] \\
\hline $\mathrm{NH}_{3}$ & $50 / 200$ & $4.3 / 8.4$ & 250 & $\mathrm{ZnO}$ (film, porous) & {$[253]$} \\
\hline $\mathrm{NO}_{\mathrm{x}}$ & $0.1 / 1 / 10$ & $2 / 65 / 213$ & 120 & $\mathrm{In}_{2} \mathrm{O}_{3}$ (forest, porous) & [158] \\
\hline NO & 20 & $203^{\mathrm{a}}$ & 200 & $\mathrm{WO}_{3}$ (flower, porous rough petals) & {$[56]$} \\
\hline
\end{tabular}

${ }^{\text {a }}$ For an oxygen-free reference atmosphere.

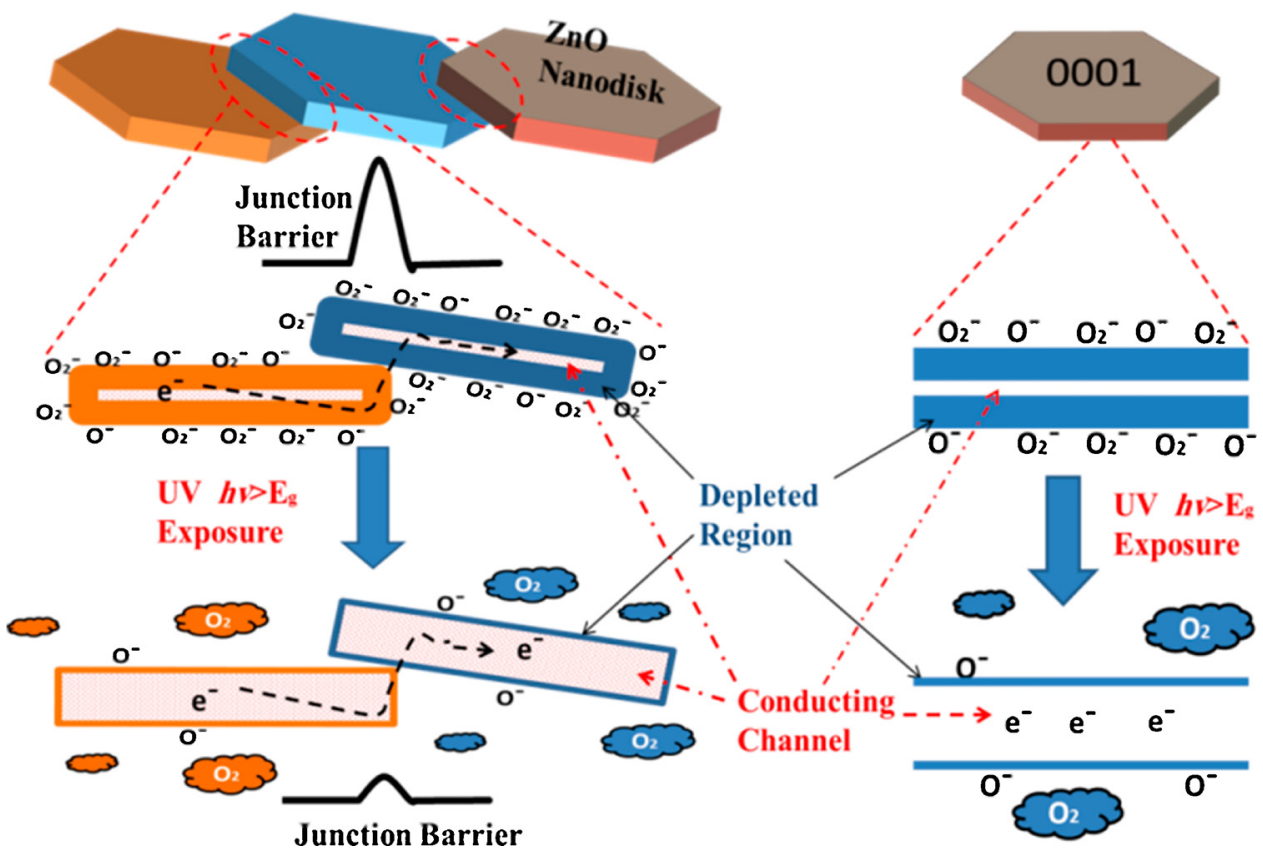

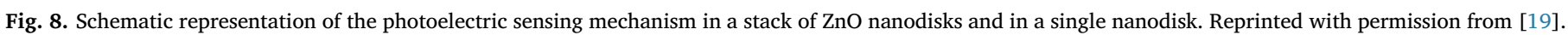
Copyright 2014 American Chemical Society.

used for the detection of many different target gases, but is almost always outperformed by other metal oxides in terms of response. For selective detection of acetic acid and glycol only $\mathrm{SnO}_{2}$-based 2D sensors were found.

As for the relation between 2D nanoflake thickness and sensor response, in principle, thinner nanoflakes yield more surface area and thus more active sensing sites per unit volume of metal oxide. However, the used amount of metal oxide is often not of critical importance in sensor design. The active surface area of a sensor can then also be tuned by e.g. changing the dimensions and architecture of the substrate and the packing density of the metal oxide nanoflakes. Since reports on sensor performance generally do not consider the amount of metal oxide used in a sensor, care must be taken in interpreting correlations between response and nanoflake dimensions or specific surface areas. The various best-performing sensors discussed above have nanoflake thicknesses over the entire size range up to $50 \mathrm{~nm}$ (the limit of this review), not indicating a general design rule for sensor optimization.

In addition to the metal oxide loading on a specific device, other fabrication and operation aspects can also significantly influence the sensor performance. The electrical contact depends on the bonding between the sensing material and the device and it may thus be advantageous to grow 2D-based architectures directly onto the sensing device. However, morphological evolution during subsequent processing of the sensor can also be detrimental [259]. As for operation 
conditions, sensor responses and selectivities vary with e.g. the gas flow rate [260], the environmental humidity [122] and the operation temperature. Combined signals may be deconvoluted by applying temperature profiles to a single sensor [261] or by using so-called electronic noses, i.e. arrays of different sensors of which the responses are processed with pattern recognition software [262]. Resistive switching, i.e. tuning the metal oxide resistivity by applying a voltage bias, can also be used to increase selectivities and deconvolute combined signals [263].

\section{2D nanoflakes for radiation sensing}

Few examples have been reported of 2D nanoflake sensors for detection of radiation. Alenezi et al. have reported on UV sensing with 2D ZnO nanodisks of $10-100 \mathrm{~nm}$ thickness, employing a photoelectric sensing mechanism [19]. UV irradiation generates electron-hole pairs in the metal oxide lattice. The holes migrate to the surface and are neutralized by adsorbed oxygen ions, while the electrons increase the conductivity in the metal oxide phase. Sensing was demonstrated with both individual and stacked $\mathrm{ZnO}$ nanodisks and the conceptual difference between both cases is schematically indicated in Fig. 8 [19]. Here the junction barriers change because of UV-induced fluctuations in the ionosorbed oxygen population, but the same principle holds for fluctuations of ionosorbed species induced by reactive gases as discussed in Section 4. The tunnel current across the junction barriers between stacked nanodisks is exponentially related to the barrier height and thus highly sensitive to small changes. The sensor response was about 1000 for a single nanodisk and about 1500 for a stack of nanodisks. The single-nanodisk detector showed a photoresponsivity of $3386 \mathrm{~A} \mathrm{~W}^{-1}$ at $3 \mathrm{~V}$. Hoa et al. have prepared a photoresistive sensor with tree-like structures of 1D ZnO nanorods decorated with $10-20 \mathrm{~nm}$ thick $2 \mathrm{D} \mathrm{NiO}$ nanoflakes and thus containing many $p$ - $n$ junctions [44]. The response reached over $400 \%$ after UV exposure for about $2 \mathrm{~min}$ and still increased significantly, yielding a response improvement of 1-2 orders of magnitude as compared to both metal oxides separately. Uthirakumar et al. have increased the UV sensing performance of polymethylmethacrylate films by incorporating $0.2 \% \mathrm{CuO}$ nanoflakes, resulting in a more than threefold increase of UV absorption capability [264].

\section{Perspective}

In the field of gas sensors, the concept of using 2D metal oxides is well established. Proof-of-principle sensor devices have been prepared with many different materials via easy and scalable routes and several studies have demonstrated competitive performances. However, further device optimization is needed to enable widespread application in industry and day-to-day life. The geometrical benefits of 2D nanoflakes can be exploited best when they are assembled in 3D hierarchical architectures with moderate packing density to ensure extensive surface exposure. Achieving high selectivities is a difficult challenge with the intrinsically unselective chemiresistive sensing mechanism, but various routes can be explored in addition to the widely investigated approach of chemical sensitization (adding catalysts). For example, illumination of metal oxide sensing elements either above or below their band gap has been proposed to facilitate (selective) desorption of surface species [116]. This increases reversibility and selectivity at relatively low operation temperatures. An alternative approach is to integrate the sensor with a permselective membrane. Kato et al. have reported the use of cross-linked polysiloxane monolayers on top of sensor electrodes to detect NO in solution while preventing interfering species such as nitrite, dopamine, adrenalin and uric acid from reaching the electrode surface [265,266]. Recently, incorporation of zeolites as both filtering and catalytic component has been investigated extensively because it enables discrimination based on molecular size, shape and affinity [117,267]. Membrane layers with somewhat larger pores can induce discrimination based on molecular weight (exploit Knudsen diffusion) [117]. Finally, exploiting particular surface energy landscapes via crystal facet engineering is a promising road towards higher and finetuned sensor selectivities. Though facet engineering has been applied in several cases to promote specific chemical interactions, it is not yet generally adopted as point of consideration.

Solute sensing with 2D metal oxides is still relatively new, but pioneering reports already set the bar in minimizing the detection limit. Sensing in solution is particularly suitable for exploiting mono- or fewlayer nanosheets that do not have the rigidity to form and maintain hierarchical assemblies under dry conditions. Keeping these ultrathin crystallites in suspension yields a relatively robust and easy-to-handle system that provides full surface exposure of the nanosheets. Mono- or few-layer crystallites generally provide unsurpassed structural and chemical surface homogeneity, which is favorable for achieving welldefined sensor responses. Also, new sensing strategies may be developed based on quantum confinement effects in ultrathin nanosheets. As for plasmonic sensing, this generally varies with the shape and size of nanoparticles [268] and thus performances may be improved by controlling the size of $2 \mathrm{D}$ nanoflakes. A new and still unexplored strategy to modulate the selectivity of $2 \mathrm{D}$ sensing elements further is to introduce specific adsorption sites using controlled ion doping strategies. Doping with aliovalent dopants will affect both the nanosheet conductivity and may introduce (redox-active) surface sites for molecular or ionic recognition.

\section{References}

[1] H. Wang, A.L. Rogach, Hierarchical SnO2 nanostructures: recent advances in design, synthesis, and applications, Chem. Mater. 26 (2014) 123-133.

[2] T. Li, W. Zeng, H. Long, Z. Wang, Nanosheet-assembled hierarchical SnO2 nanostructures for efficient gas-sensing applications, Sens. Actuators B Chem. 231 (2016) 120-128.

[3] H. Wang, K. Dou, W.Y. Teoh, Y. Zhan, T.F. Hung, F. Zhang, J. Xu, R. Zhang, A.L. Rogach, Engineering of facets band structure, and gas-sensing properties of hierarchical Sn2+-doped SnO2 nanostructures, Adv. Funct. Mater. 23 (2013) 4847-4853.

[4] M.R. Alenezi, A.S. Alshammari, K.D.G.I. Jayawardena, M.J. Beliatis, S.J. Henley, S.R.P. Silva, Role of the exposed polar facets in the performance of thermally and UV activated ZnO nanostructured gas sensors, J. Phys. Chem. C. 117 (2013) 17850-17858.

[5] N. Sakai, Y. Ebina, K. Takada, T. Sasaki, Electronic band structure of titania semiconductor nanosheets revealed by electrochemical and photoelectrochemical studies, J. Am. Chem. Soc. 126 (2004) 5851-5858.

[6] Y. Omomo, T. Sasaki, L. Wang, M. Watanabe, Redoxable nanosheet crystallites of $\mathrm{MnO} 2$ derived via delamination of a layered manganese oxide, J. Am. Chem. Soc. 125 (2003) 3568-3575.

[7] R. Zhang, W. Chen, Recent advances in graphene-based nanomaterials for fabricating electrochemical hydrogen peroxide sensors, Biosens. Bioelectron. 89 (2017) 249-268.

[8] X. Bo, M. Zhou, L. Guo, Electrochemical sensors and biosensors based on less aggregated graphene, Biosens. Bioelectron. 89 (2017) 167-186.

[9] S. Campuzano, M. Pedrero, G.-P. Nikoleli, J.M. Pingarrón, D.P. Nikolelis, Hybrid 2D-nanomaterials-based electrochemical immunosensing strategies for clinical biomarkers determination, Biosens. Bioelectron. 89 (2017) 269-279.

[10] T. Zhang, J. Liu, C. Wang, X. Leng, Y. Xiao, L. Fu, Synthesis of graphene and related two-dimensional materials for bioelectronics devices, Biosens. Bioelectron. 89 (2017) 28-42.

[11] W. Fu, L. Jiang, E.P. van Geest, L.M.C. Lima, G.F. Schneider, Sensing at the surface of graphene field-effect transistors, Adv. Mater. 29 (2017) 1603610.

[12] J. Xu, Y. Wang, S. Hu, Nanocomposites of graphene and graphene oxides: synthesis, molecular functionalization and application in electrochemical sensors and biosensors. A review, Microchim. Acta 184 (2017) 1-44.

[13] L. Wang, Q. Xiong, F. Xiao, H. Duan, 2D nanomaterials based electrochemical biosensors for cancer diagnosis, Biosens. Bioelectron. 89 (2017) 136-151.

[14] P. Bollella, G. Fusco, C. Tortolini, G. Sanzò, G. Favero, L. Gorton, R. Antiochia, Beyond graphene: electrochemical sensors and biosensors for biomarkers detec tion, Biosens. Bioelectron. 89 (2017) 152-166.

[15] J. Ping, Z. Fan, M. Sindoro, Y. Ying, H. Zhang, Recent advances in sensing applications of two-dimensional transition metal dichalcogenide nanosheets and their composites, Adv. Funct. Mater. 27 (2017) 1605817.

[16] S. Yang, C. Jiang, S. Wei, Gas sensing in 2D materials, Appl. Phys. Rev. 4 (2017) 21304.

[17] X. Liu, T. Ma, N. Pinna, J. Zhang, Two-dimensional nanostructured materials for gas sensing, Adv. Funct. Mater. 27 (2017) 1702168.

[18] Y. Shu, J. Xu, J. Chen, Q. Xu, X. Xiao, D. Jin, H. Pang, X. Hu, Ultrasensitive electrochemical detection of $\mathrm{H} 2 \mathrm{O} 2$ in living cells based on ultrathin $\mathrm{MnO} 2$ 
nanosheets, Sens. Actuators B Chem. 252 (2017) 72-78.

[19] M.R. Alenezi, A.S. Alshammari, T.H. Alzanki, P. Jarowski, S.J. Henley, S.R.P. Silva, ZnO nanodisk based UV detectors with printed electrodes, Langmuir 30 (2014) 3913-3921.

[20] J. Hu, Y. Liang, Y. Sun, Z. Zhao, M. Zhang, P. Li, W. Zhang, Y. Chen, S. Zhuiykov, Highly sensitive NO2 detection on ppb level by devices based on Pd-loaded In2O3 hierarchical microstructures, Sen. Actuators B Chem. 252 (2017) 116-126.

[21] Y. Zhang, L. Xie, C. Yuan, C. Zhang, S. Liu, Y. Peng, H. Li, M. Zhang, Preparation of 3D rose-like nickel oxide nanoparticles by electrodeposition method and application in gas sensors, J. Mater. Sci. Mater. Electron. 27 (2016) 1817-1827.

[22] H. Yu, T. Yang, Z. Wang, Z. Li, B. Xiao, Q. Zhao, M. Zhang, Facile synthesis cedarlike $\mathrm{SnO} 2$ hierarchical micro-nanostructures with improved formaldehyde gas sensing characteristics, J. Alloys Compd. 724 (2017) 121-129.

[23] L.T. Hoa, H.N. Tien, V.H. Luan, J.S. Chung, S.H. Hur, Fabrication of a novel 2D graphene/2D-NiO nanosheet-based hybrid nanostructure and its use in highly sensitive NO2 sensors, Sens. Actuators B Chem. 185 (2013) 701-705.

[24] Y. Zeng, L. Qiao, Y. Bing, M. Wen, B. Zou, W. Zheng, T. Zhang, G. Zou, Development of microstructure CO sensor based on hierarchically porous $\mathrm{ZnO}$ nanosheet thin films, Sens. Actuators B Chem. 173 (2012) 897-902.

[25] Z. Cui, H. Yin, Q. Nie, Controllable preparation of hierarchically core-shell structure $\mathrm{NiO} / \mathrm{C}$ microspheres for non-enzymatic glucose sensor, J. Alloys Compd. 632 (2015) 402-407.

[26] L. Gao, Z. Cheng, Q. Xiang, Y. Zhang, J. Xu, Porous corundum-type In2O3 nanosheets: synthesis and NO2 sensing properties, Sen. Actuators B Chem. 208 (2015) 436-443.

[27] X. Xu, P. Zhao, D. Wang, P. Sun, L. You, Y. Sun, X. Liang, F. Liu, H. Chen, G. Lu, Preparation and gas sensing properties of hierarchical flower-like In2O3 microspheres, Sens. Actuators B Chem. 176 (2013) 405-412.

[28] Y. Zhao, J. Zhao, Y. Li, D. Ma, S. Hou, L. Li, X. Hao, Z. Wang, Room temperature synthesis of 2D CuO nanoleaves in aqueous solution, Nanotechnology 22 (2011) 115604.

[29] J. Liu, T. Luo, F. Meng, K. Qian, Y. Wan, J. Liu, Porous hierarchical In2O3 micro-/ nanostructures: preparation, formation mechanism, and their application in gas sensors for noxious volatile organic compound detection, J. Phys. Chem. C. 114 (2010) 4887-4894.

[30] J. Cao, S. Wang, H. Zhang, Controllable synthesis of zinc oxide hierarchical architectures and their excellent formaldehyde gas sensing performances, Mater. Lett. 202 (2017) 44-47.

[31] J. Cui, J. Sun, X. Liu, J. Li, X. Ma, T. Chen, Fabrication of hierarchical flower-like porous $\mathrm{ZnO}$ nanostructures from layered $\mathrm{ZnC} 2 \mathrm{O} 4$. $3 \mathrm{Zn}(\mathrm{OH}) 2$ and gas sensing properties, Appl. Surf. Sci. 308 (2014) 17-23.

[32] T.T. Wang, S.Y. Ma, L. Cheng, X.L. Xu, J. Luo, X.H. Jiang, W.Q. Li, W.X. Jin, X.X. Sun, Performance of 3D SnO2 microstructure with porous nanosheets for acetic acid sensing, Mater. Lett. 142 (2015) 141-144.

[33] T. Yu, X. Cheng, X. Zhang, L. Sui, Y. Xu, S. Gao, H. Zhao, L. Huo, Highly sensitive $\mathrm{H} 2 \mathrm{~S}$ detection sensors at low temperature based on hierarchically structured NiO porous nanowall arrays, J. Mater. Chem. A. 3 (2015) 11991-11999.

[34] X. San, G. Zhao, G. Wang, Y. Shen, D. Meng, Y. Zhang, F. Meng, Assembly of 3D flower-like NiO hierarchical architectures by 2D nanosheets: synthesis and their sensing properties to formaldehyde, RSC Adv. 7 (2017) 3540-3549.

[35] H. Pang, Y. Dong, S.L. Ting, J. Lu, C.M. Li, D.-H. Kim, P. Chen, 2D single- or double-layered vanadium oxide nanosheet assembled 3D microflowers: controlled synthesis, growth mechanism, and applications, Nanoscale 5 (2013) 7790-7794.

[36] X. San, G. Wang, B. Liang, J. Ma, D. Meng, Y. Shen, Flower-like NiO hierarchical microspheres self-assembled with nanosheets: surfactant-free solvothermal synthesis and their gas sensing properties, J. Alloys Compd. 636 (2015) 357-362.

[37] J. Huang, X. Xu, C. Gu, M. Yang, M. Yang, J. Liu, Large-scale synthesis of hydrated tungsten oxide 3D architectures by a simple chemical solution route and their gassensing properties, J. Mater. Chem. 21 (2011) 13283-13289.

[38] D. He, X. He, K. Wang, X. Yang, X. Yang, X. Li, Z. Zou, Nanometer-sized manganese oxide-quenched fluorescent oligonucleotides: an effective sensing platform for probing biomolecular interactions, Chem. Commun. 50 (2014) 11049-11052.

[39] L. Lin, T. Liu, W. Yu, Z. Gou, W. Zeng, Synthesis of multifarious hierarchical flower-like NiO and their gas-sensing properties, Mater. Res. Bull. 48 (2013) $2730-2736$.

[40] J. Wang, W. Zeng, Z. Wang, Assembly of 2D nanosheets into 3D flower-like NiO: Synthesis and the influence of petal thickness on gas-sensing properties, Ceram. Int. 42 (2016) $4567-4573$.

[41] S. Cao, H. Chen, T. Han, C. Zhao, L. Peng, Rose-like Cu2O nanoflowers via hydrothermal synthesis and their gas sensing properties, Mater. Lett. 180 (2016) $135-139$.

[42] X. Zhou, X. Li, H. Sun, P. Sun, X. Liang, F. Liu, X. Hu, G. Lu, Nanosheet-assembled ZnFe2O4 hollow microspheres for high-sensitive acetone sensor, ACS Appl. Mater. Interfaces. 7 (2015) 15414-15421.

[43] L. Li, C. Zhang, R. Zhang, X. Gao, S. He, M. Liu, X. Li, W. Chen, 2D ultrathin Co3O4 nanosheet array deposited on 3D carbon foam for enhanced ethanol gas sensing application, Sens. Actuators B Chem. 244 (2017) 664-672.

[44] L.T. Hoa, H.N. Tien, S.H. Hur, A highly sensitive UV sensor composed of 2D NiO nanosheets and 1D ZnO nanorods fabricated by a hydrothermal process, Sens. Actuators A Phys. 207 (2014) 20-24.

[45] C. Wang, J. Liu, Q. Yang, P. Sun, Y. Gao, F. Liu, J. Zheng, G. Lu, Ultrasensitive and low detection limit of acetone gas sensor based on W-doped NiO hierarchical nanostructure, Sens. Actuators B Chem. 220 (2015) 59-67.

[46] Q. Gao, W. Zeng, R. Miao, Synthesis of multifarious hierarchical flower-like NiO and their gas-sensing properties, J. Mater. Sci. Mater. Electron. 27 (2016) 9410-9416.
[47] Y. Li, Morphology-controllable synthesis of three-dimensional a-MoO3 and their applications in gas sensing, Phys. E 94 (2017) 22-24.

[48] Y.-L.T. Ngo, S.H. Hur, Low-temperature NO2 gas sensor fabricated with $\mathrm{NiO}$ and reduced graphene oxide hybrid structure, Mater. Res. Bull. 84 (2016) 168-176.

[49] F. Meng, S. Ge, Y. Jia, B. Sun, Y. Sun, C. Wang, H. Wu, Z. Jin, M. Li, Interlaced nanoflake-assembled flower-like hierarchical $\mathrm{ZnO}$ microspheres prepared by bisolvents and their sensing properties to ethanol, J. Alloys Compd. 632 (2015) 645-650.

[50] R. Miao, W. Zeng, Q. Gao, SDS-assisted hydrothermal synthesis of NiO flake-flowe architectures with enhanced gas-sensing properties, Appl. Surf. Sci. 384 (2016) 304-310.

[51] J. Hu, X. Wang, M. Zhang, Y. Sun, P. Li, W. Zhang, K. Lian, L. Chen, Y. Chen, Synthesis and characterization of flower-like $\mathrm{MoO} 3 / \mathrm{In} 2 \mathrm{O} 3$ microstructures for highly sensitive ethanol detection, RSC Adv. 7 (2017) 23478-23485.

[52] W. Guo, ZnO nanosheets assembled different hierarchical structures and their gas sensing properties, J. Mater. Sci. Mater. Electron. 27 (2016) 7302-7310.

[53] W. Guo, T. Liu, W. Zeng, D. Liu, Y. Chen, Z. Wang, Gas-sensing property improvement of ZnO by hierarchical flower-like architectures, Mater. Lett. 65 (2011) 3384-3387.

[54] Q. Zhou, W. Chen, J. Li, C. Tang, H. Zhang, Nanosheet-assembled flower-like SnO2 hierarchical structures with enhanced gas-sensing performance, Mater. Lett. 161 (2015) 499-502.

[55] W. Zeng, H. Zhang, Y. Li, W. Chen, Z. Wang, Hydrothermal synthesis of hier archical flower-like $\mathrm{SnO} 2$ nanostructures with enhanced ethanol gas sensing properties, Mater. Res. Bull. 57 (2014) 91-96.

[56] Z.-X. Cai, H.-Y. Li, J.-C. Ding, X. Guo, Hierarchical flowerlike WO3 nanostructure assembled by porous nanoflakes for enhanced NO gas sensing, Sens. Actuators B Chem. 246 (2017) 225-234.

[57] Q. Wang, C. Wang, H. Sun, P. Sun, Y. Wang, J. Lin, G. Lu, Microwave assisted synthesis of hierarchical $\mathrm{Pd} / \mathrm{SnO} 2$ nanostructures for $\mathrm{CO}$ gas sensor, Sens. Actuators B Chem. 222 (2016) 257-263.

[58] W. Tan, J. Tan, L. Fan, Z. Yu, J. Qian, X. Huang, Fe2O3-loaded NiO nanosheets for fast response/recovery and high response gas sensor, Sens. Actuators B Chem. 256 (2018) 282-293.

[59] X. Li, F. Wang, J. Tu, H.U. Shah, J. Hu, Y. Li, Y. Lu, M. Xu, Synthesis and ethano] sensing properties of novel hierarchical Sn3O4 nanoflowers, J. Nanomater. 2015 (2015) 980170.

[60] X. Qu, M. Wang, W. Sun, R. Yang, Hierarchical flower-like ZnO microstructures: preparation, formation mechanism and application in gas sensor, J. Mater. Sci. Mater. Electron. (2017), http://dx.doi.org/10.1007/s10854-017-7338-z.

[61] H. Yan, P. Song, S. Zhang, Z. Yang, Q. Wang, Facile fabrication and enhanced gas sensing properties of hierarchical MoO3 nanostructures, RSC Adv. 5 (2015) $72728-72735$.

[62] J. Liu, F. Meng, Y. Zhong, J. Liu, G. Chen, Y. Wan, K. Qian, S. Mouli, Assembly formation mechanism, and enhanced gas-sensing properties of porous and hierarchical SnO2 hollow nanostructures, J. Mater. Res. 25 (2010) 1992-2000.

[63] Y. Chen, L. Yu, Q. Li, Y. Wu, Q. Li, T. Wang, An evolution from 3D face-centeredcubic $\mathrm{ZnSnO} 3$ nanocubes to 2D orthorhombic $\mathrm{ZnSnO} 3$ nanosheets with excellent gas sensing performance, Nanotechnology 23 (2012) 415501.

[64] M. Yin, S. Liu, Controlled ZnO hierarchical structure for improved gas sensing performance, Sens. Actuators B Chem. 209 (2015) 343-351.

[65] S. Wang, Z. Li, P. Wang, C. Xiao, R. Zhao, B. Xiao, T. Yang, M. Zhang, Facile synthesis and enhanced gas sensing properties of In2O3 nanoparticle-decorated ZnO hierarchical architectures, CrystEngComm 16 (2014) 5716-5723.

[66] S. Wang, P. Wang, Z. Li, C. Xiao, B. Xiao, R. Zhao, T. Yang, M. Zhang, Highly enhanced methanol gas sensing properties by Pd0.5Pd304 nanoparticle loaded ZnO hierarchical structures, RSC Adv. 4 (2014) 35375-35382.

[67] W. Zhai, C. Wang, P. Yu, Y. Wang, L. Mao, Single-layer MnO2 nanosheets suppressed fluorescence of 7-hydroxycoumarin: mechanistic study and application fo sensitive sensing of ascorbic acid in vivo, Anal. Chem. 86 (2014) 12206-12213.

[68] S. Bai, K. Zhang, R. Luo, D. Li, A. Chen, C.-C. Liu, Sonochemical synthesis of hierarchically assembled tungsten oxides with excellent NO2-sensing properties, Mater. Lett. 111 (2013) 32-34.

[69] X. Shen, Q. Liu, Z. Ji, G. Zhu, H. Zhou, K. Chen, Controlled synthesis and gas sensing properties of porous $\mathrm{Fe} 2 \mathrm{O} 3 / \mathrm{NiO}$ hierarchical nanostructures, CrystEngComm 17 (2015) 5522-5529.

[70] M. Hu, Y. Yamauchi, Synthesis of a titanium-containing Prussian-blue analogue with a well-defined cube structure and its thermal conversion into a nanoporous titanium-iron-based oxide, Chem. - An Asian J. 6 (2011) 2282-2286.

[71] C. Yuan, H. Li, L. Xie, F. Wang, H. Deng, F. Chang, Y. Sun, Flower-like NiO nanostructures synthesized by electrodeposition method for efficient detection of toluene gas, RSC Adv. 5 (2015) 92128-92133.

[72] M. Tonezzer, S. Iannotta, H2 sensing properties of two-dimensional zinc oxide nanostructures, Talanta 122 (2014) 201-208.

[73] W. Maziarz, A. Kusior, A. Trenczek-Zajac, Nanostructured TiO2-based gas sensors with enhanced sensitivity to reducing gases, Beilstein J. Nanotechnol. 7 (2016) $1718-1726$.

[74] S.-J. Choi, J.-S. Jang, H.J. Park, I.-D. Kim, Optically sintered 2D RuO2 nanosheets temperature-controlled NO2 reaction, Adv. Funct. Mater. 27 (2017) 1606026.

[75] M.M.Y.A. Alsaif, K. Latham, M.R. Field, D.D. Yao, N.V. Medhekar, G.A. Beane, R.B. Kaner, S.P. Russo, J.Z. Ou, K. Kalantar-zadeh, Tunable plasmon resonances in two-dimensional molybdenum oxide nanoflakes, Adv. Mater. 26 (2014) 3931-3937.

[76] M.M.Y.A. Alsaif, M.R. Field, T. Daeneke, A.F. Chrimes, W. Zhang, B.J. Carey, K.J. Berean, S. Walia, J. Van Embden, B. Zhang, K. Latham, K. Kalantar-zadeh, J.Z. Ou, Exfoliation solvent dependent plasmon resonances in two-dimensional 
sub-stoichiometric molybdenum oxide nanoflakes, ACS Appl. Mater. Interfaces. 8 (2016) 3482-3493.

[77] M.M.Y.A. Alsaif, M.R. Field, B.J. Murdoch, T. Daeneke, K. Latham, A.F. Chrimes, A.S. Zoolfakar, S.P. Russo, J.Z. Ou, K. Kalantar-zadeh, Substoichiometric two-dimensional molybdenum oxide flakes: a plasmonic gas sensing platform, Nanoscale 6 (2014) 12780-12791.

[78] D. Chen, X. Hou, H. Wen, Y. Wang, H. Wang, X. Li, R. Zhang, H. Lu, H. Xu, S. Guan, J. Sun, L. Gao, The enhanced alcohol-sensing response of ultrathin WO3 nanoplates, Nanotechnology 21 (2010) 35501.

[79] H. Yuan, D. Dubbink, R. Besselink, J.E. Ten Elshof, The rapid exfoliation and subsequent restacking of layered titanates driven by an acid-base reaction, Angew. Chemie - Int. Ed. 54 (2015) 9239-9243.

[80] G. Blatter, F. Greuter, Carrier transport through grain boundaries in semiconductors, Phys. Rev. B. 33 (1986) 3952-3966.

[81] E. Comini, Metal oxide nano-crystals for gas sensing, Anal. Chim. Acta 568 (2006) $28-40$.

[82] G. Korotcenkov, The role of morphology and crystallographic structure of metal oxides in response of conductometric-type gas sensors, Mater. Sci. Eng. R 61 (2008) 1-39.

[83] Y. Yuan, S. Wu, F. Shu, Z. Liu, An MnO2 nanosheet as a label-free nanoplatform for homogeneous biosensing, Chem. Commun. 50 (2014) 1095-1097.

[84] N. Dhenadhayalan, K. Yadav, M.I. Sriram, H.-L. Lee, K.-C. Lin, Ultra-sensitive DNA sensing of a prostate-specific antigen based on 2D nanosheets in live cells, Nanoscale 9 (2017) 12087-12095.

[85] S. Lin, H. Cheng, Q. Ouyang, H. Wei, Deciphering the quenching mechanism of 2D $\mathrm{MnO} 2$ nanosheets towards Au nanocluster fluorescence to design effective glutathione biosensors, Anal. Methods 8 (2016) 3935-3940.

[86] S. Balendhran, S. Walia, M. Alsaif, E.P. Nguyen, J.Z. Ou, S. Zhuiykov, S. Sriram, M. Bhaskaran, K. Kalantar-zadeh, Field effect biosensing platform based on 2D aMoO3, ACS Nano 7 (2013) 9753-9760.

[87] L.-C. Jiang, W.-D. Zhang, A highly sensitive nonenzymatic glucose sensor based on $\mathrm{CuO}$ nanoparticles-modified carbon nanotube electrode, Biosens. Bioelectron. 25 (2010) 1402-1407.

[88] G.V. Naik, V.M. Shalaev, A. Boltasseva, Alternative plasmonic materials: beyond gold and silver, Adv. Mater. 25 (2013) 3264-3294.

[89] K. Manthiram, A.P. Alivisatos, Tunable localized surface plasmon resonances in tungsten oxide nanocrystals, J. Am. Chem. Soc. 134 (2012) 3995-3998.

[90] M.R. Mahmoudian, W.J. Basirun, P.M. Woi, M. Sookhakian, R. Yousefi, H. Ghadimi, Y. Alias, Synthesis and characterization of Co3O4 ultra-nanosheets and $\mathrm{Co} 3 \mathrm{O} 4$ ultra-nanosheet-Ni(OH)2 as non-enzymatic electrochemical sensors for glucose detection, Mater. Sci. Eng. C 59 (2016) 500-508.

[91] K. Yang, M. Zeng, X. Fu, J. Li, N. Ma, L. Tao, Establishing biodegradable singlelayer $\mathrm{MnO} 2$ nanosheets as a platform for live cell microRNA sensing, RSC Adv. 5 (2015) 104245-104249.

[92] J. Yuan, Y. Cen, X.-J. Kong, S. Wu, C.-L. Liu, R.-Q. Yu, X. Chu, MnO2-nanosheetmodified upconversion nanosystem for sensitive turn-on fluorescence detection of H2O2 and glucose in blood, ACS Appl. Mater. Interfaces 7 (2015) 10548-10555.

[93] R. Deng, X. Xie, M. Vendrell, Y.-T. Chang, X. Liu, Intracellular glutathione detection using MnO2-nanosheet-modified upconversion nanoparticles, J. Am. Chem. Soc. 133 (2011) 20168-20171.

[94] N. Li, W. Diao, Y. Han, W. Pan, T. Zhang, B. Tang, MnO2-modified persistent luminescence nanoparticles for detection and imaging of glutathione in living cells and in vivo, Chem. - A Eur. J. 20 (2014) 16488-16491.

[95] Y. Wang, K. Jiang, J. Zhu, L. Zhang, H. Lin, A FRET-based carbon dot?MnO2 nanosheet architecture for glutathione sensing in human whole blood samples, Chem. Commun. 51 (2015) 12748-12751.

[96] X. Wang, D. Wang, Y. Guo, C. Yang, X. Liu, A. Iqbal, W. Liu, W. Qin, D. Yan, H. Guo, Fluorescent glutathione probe based on $\mathrm{MnO}$-phenol formaldehyde resin nanocomposite, Biosens. Bioelectron. 77 (2016) 299-305.

[97] H. Ma, X. Li, X. Liu, M. Deng, X. Wang, A. Iqbal, W. Liu, W. Qin, Fluorescent glutathione probe based on $\mathrm{MnO} 2-\mathrm{Si}$ quantum dots nanocomposite directly used for intracellular glutathione imaging, Sens. Actuators B Chem. 255 (2018) 1687-1693.

[98] X. Tan, L. Wang, C. Cheng, X. Yan, B. Shen, J. Zhang, Plasmonic MoO3-x@MoO3 nanosheets for highly sensitive SERS detection through nanoshell-isolated electromagnetic enhancement, Chem. Commun. 52 (2016) 2893-2896.

[99] S. Yuan, D. Peng, D. Song, J. Gong, Layered titanate nanosheets as an enhanced sensing platform for ultrasensitive stripping voltammetric detection of mercury (II), Sen. Actuators B Chem. 181 (2013) 432-438.

[100] Y.-L.T. Ngo, L.T. Hoa, J.S. Chung, S.H. Hur, Multi-dimensional Ag/NiO/reduced graphene oxide nanostructures for a highly sensitive non-enzymatic glucose sensor, J. Alloys Compd. 712 (2017) 742-751.

[101] J. Yang, M. Cho, C. Pang, Y. Lee, Highly sensitive non-enzymatic glucose sensor based on over-oxidized polypyrrole nanowires modified with $\mathrm{Ni}(\mathrm{OH}) 2$ nanoflakes, Sens. Actuators B Chem. 211 (2015) 93-101.

[102] X.H. Xia, J.P. Tu, J. Zhang, X.L. Wang, W.K. Zhang, H. Huang, Electrochromic properties of porous NiO thin films prepared by a chemical bath deposition, Sol. Energy Mater. Sol. Cells 92 (2008) 628-633.

[103] P. Lu, Y. Lei, S. Lu, Q. Wang, Q. Liu, Three-dimensional roselike a-Ni(OH)2 assembled from nanosheet building blocks for non-enzymatic glucose detection, Anal. Chim. Acta 880 (2015) 42-51.

[104] P. Lu, Q. Liu, Y. Xiong, Q. Wang, Y. Lei, S. Lu, L. Lu, L. Yao, Nanosheets-assembled hierarchical microstructured $\mathrm{Ni}(\mathrm{OH}) 2$ hollow spheres for highly sensitive enzymefree glucose sensors, Electrochim. Acta 168 (2015) 148-156.

[105] H. Yang, G. Gao, F. Teng, W. Liu, S. Chen, Z. Ge, Nickel hydroxide nanoflowers for a nonenzymatic electrochemical glucose sensor, J. Electrochem. Soc. 161 (2014)
B216-B219.

[106] K. Xia, C. Yang, Y. Chen, L. Tian, Y. Su, J. Wang, L. Li, In situ fabrication of Ni(OH) 2 flakes on $\mathrm{Ni}$ foam through electrochemical corrosion as high sensitive and stable binder-free electrode for glucose sensing, Sens. Actuators B Chem. 240 (2017) 979-987.

[107] G.T.S. How, A. Pandikumar, H.N. Ming, L.H. Ngee, Highly exposed $\{001\}$ facets of titanium dioxide modified with reduced graphene oxide for dopamine sensing, Sci. Rep. 4 (2014) 5044.

[108] P.K. Vabbina, A. Kaushik, N. Pokhrel, S. Bhansali, N. Pala, Electrochemical cortisol immunosensors based on sonochemically synthesized zinc oxide 1D nanorods and 2D nanoflakes, Biosens. Bioelectron. 63 (2015) 124-130.

[109] K. Kalantar-zadeh, J.Z. Ou, T. Daeneke, A. Mitchell, T. Sasaki, M.S. Fuhrer, Two dimensional and layered transition metal oxides, Appl. Mater. Today 5 (2016) 73-89.

[110] P.R. Solanki, A. Kaushik, V.V. Agrawal, B.D. Malhotra, Nanostructured metal oxide-based biosensors, NPG Asia Mater. 3 (2011) 17-24.

[111] S. Marimuthu, Y. Mohamad, Needle-like polypyrrole-NiO composite for non-enzymatic detection of glucose, Synth. Met. 207 (2015) 35-41.

[112] G. Wu, Y.-Z. Fang, S. Yang, J.R. Lupton, N.D. Turner, Glutathione metabolism and its implications for health, J. Nutr. 134 (2004) 489-492.

[113] D. Zhang, G. Li, X. Yang, J.C. Yu, A micrometer-size TiO2 single-crystal photocatalyst with remarkable $80 \%$ level of reactive facets, Chem. Commun. 438 (2009) 4381-4383.

[114] J.S. Chen, Y.L. Tan, C.M. Li, Y.L. Cheah, D. Luan, Constructing hierarchical spheres from large ultrathin anatase TiO2 nanosheets with nearly 100\% exposed (001) facets for fast reversible lithium storage, J. Am. Chem. Soc. 132 (2010) 6124-6130.

[115] H.-J. Kim, J.-H. Lee, Highly sensitive and selective gas sensors using p-type oxide semiconductors: overview, Sens. Actuators B Chem. 192 (2014) 607-627.

[116] I.-D. Kim, A. Rothschild, H.L. Tuller, Advances and new directions in gas-sensing devices, Acta Mater. 61 (2013) 974-1000.

[117] J. Zhang, Z. Qin, D. Zeng, C. Xie, Metal-oxide-semiconductor based gas sensors: screening, preparation, and integration, Phys. Chem. Chem. Phys. 19 (2017) 6313-6329.

[118] A. Gurlo, R. Riedel, In situ and operando spectroscopy for assessing mechanisms of gas sensing, Angew. Chemie - Int. Ed. 46 (2007) 3826-3848.

[119] R. Azimirad, A.H. Bayani, S. Safa, The effect of concentration of H2 physisorption on the current-voltage characteristic of armchair BN nanotubes in CNT-BNNT-CNT set, Pramana - J. Phys. 87 (2016) 46.

[120] A. Ponzoni, C. Baratto, N. Cattabiani, M. Falasconi, V. Galstyan, E. Nunez Carmona, F. Rigoni, V. Sberveglieri, G. Zambotti, D. Zappa, Metal oxide gas sensors, a survey of selectivity issues addressed at the SENSOR lab, Brescia (Italy), Sensors 17 (2017) 714.

[121] M. Hübner, C.E. Simion, A. Tomescu-Stănoiu, S. Pokhrel, N. Bârsan, U. Weimar, Influence of humidity on $\mathrm{CO}$ sensing with p-type $\mathrm{CuO}$ thick film gas sensors, Sens. Actuators B Chem. 153 (2011) 347-353.

[122] H.-R. Kim, A. Haensch, I.-D. Kim, N. Barsan, U. Weimar, J.-H. Lee, The role of NiO doping in reducing the impact of humidity on the performance of SnO2-based gas sensors: synthesis strategies, and phenomenological and spectroscopic studies, Adv. Funct. Mater. 21 (2011) 4456-4463.

[123] J. Zhang, D. Zeng, O. Zhu, J. Wu, Q. Huang, C. Xie, Effect of nickel vacancies on the room-temperature $\mathrm{NO} 2$ sensing properties of mesoporous $\mathrm{NiO}$ nanosheets, $\mathrm{J}$. Phys. Chem. C 120 (2016) 3936-3945.

[124] W. Guo, Design of gas sensor based on Fe-doped ZnO nanosheet-spheres for low concentration of formaldehyde detection, J. Electrochem. Soc. 163 (2016) B517-B525.

[125] J. Liu, S. Li, B. Zhang, Y. Wang, Y. Gao, X. Liang, Y. Wang, G. Lu, Flower-like In2O3 modified by reduced graphene oxide sheets serving as a highly sensitive gas sensor for trace NO2 detection, J.Colloid Interface Sci. 504 (2017) 206-213.

[126] Y. Lu, Y. Ma, S. Ma, S. Yan, Hierarchical heterostructure of porous NiO nanosheets on flower-like $\mathrm{ZnO}$ assembled by hexagonal nanorods for high-performance gas sensor, Ceram. Int. 43 (2017) 7508-7515.

[127] Q. Wang, X. Li, F. Liu, Y. Sun, C. Wang, X. Li, P. Sun, J. Lin, G. Lu, Three-dimensional flake-flower $\mathrm{Co} / \mathrm{Sn}$ oxide composite and its excellent ethanol sensing properties, Sens. Actuators B Chem. 230 (2016) 17-24.

[128] Y. Luo, C. Zhang, B. Zheng, X. Geng, M. Debliquy, Hydrogen sensors based on noble metal doped metal-oxide semiconductor: a review, Int. J. Hydrogen Energy 42 (2017) 20386-20397.

[129] D.R. Miller, S.A. Akbar, P.A. Morris, Nanoscale metal oxide-based heterojunction for gas sensing: a review, Sensors Actuators B Chem. 204 (2014) 250-272.

[130] H.-S. Woo, C.W. Na, J.-H. Lee, Design of highly selective gas sensors via physicochemical modification of oxide nanowires: overview, Sensors 16 (2016) 1531.

[131] Q. Zhao, X. Deng, M. Ding, L. Gan, T. Zhai, X. Xu, One-pot synthesis of Zn-doped $\mathrm{SnO} 2$ nanosheet-based hierarchical architectures as a glycol gas sensor and photocatalyst, CrystEngComm 17 (2015) 4394-4401.

[132] L.T. Hoa, H.N. Tien, S.H. Hur, Fabrication of novel 2D NiO nanosheet branched on 1D-ZnO nanorod arrays for gas sensor application, J. Nanomater. 2014 (2014) 710874.

[133] L. Wang, S. Wang, H. Zhang, Y. Wang, J. Yang, W. Huang, Au-functionalized porous $\mathrm{ZnO}$ microsheets and their enhanced gas sensing properties, New J. Chem. 38 (2014) 2530-2537.

[134] X. Zhang, P. Guo, Q. Pan, K. Shi, G. Zhang, Novel p-n heterojunction Co3O4/ $\mathrm{AlOOH}$ composites materials for gas sensing at room temperature, J. Alloys Compd. 727 (2017) 514-521.

[135] J. Xiao, C. Song, W. Dong, Y. Yin, C. Li, Preparation and gas sensing properties of hierarchical flower-shaped Bi2WO6, Aust. J. Chem. 69 (2015) 107-111. 
[136] J. Xiao, W. Dong, C. Song, Y. Yu, L. Zhang, C. Li, Y. Yin, Nitrogen oxide gas-sensing characteristics of hierarchical Bi2WO6 microspheres prepared by a hydrothermal method, Mater. Sci. Semicond. Process. 40 (2015) 463-467.

[137] L.-J. Zhou, C. Li, X. Zou, J. Zhao, P.-P. Jin, L.-L. Feng, M.-H. Fan, G.-D. Li, Porous nanoplate-assembled $\mathrm{CdO} / \mathrm{ZnO}$ composite microstructures: a highly sensitive material for ethanol detection, Sens. Actuators B Chem. 197 (2014) 370-375.

[138] K. Xu, J. Zou, S. Tian, Y. Yang, F. Zeng, T. Yu, Y. Zhang, X. Jie, C. Yuan, Singlecrystalline porous nanosheets assembled hierarchical Co3O4 microspheres for enhanced gas-sensing properties to trace xylene, Sens. Actuators B Chem. 246 (2017) 68-77.

[139] S.-J. Hwang, K.-I. Choi, J.-W. Yoon, Y.C. Kang, J.-H. Lee, Pure and palladiumloaded $\mathrm{Co} 3 \mathrm{O} 4$ hollow hierarchical nanostructures with giant and ultraselective chemiresistivity to xylene and toluene, Chem. - A Eur. J. 21 (2015) 5872-5878.

[140] H. Che, A. Liu, X. Zhang, J. Hou, J. Mu, H. He, Two-dimensional nanosheetsassembled flower-like Co3O4 microspheres and their gas sensing performances, Nano 9 (2014) 1450071.

[141] K.-I. Choi, H.-R. Kim, K.-M. Kim, D. Liu, G. Cao, J.-H. Lee, C2H5OH sensing characteristics of various $\mathrm{Co} 3 \mathrm{O} 4$ nanostructures prepared by solvothermal reaction, Sens. Actuators B Chem. 146 (2010) 183-189.

[142] Z. Zhang, Z. Wen, Z. Ye, L. Zhu, Gas sensors based on ultrathin porous Co3O4 nanosheets to detect acetone at low temperature, RSC Adv. 5 (2015) 59976-59982.

[143] Y. Lin, H. Ji, Z. Shen, Q. Jia, D. Wang, Enhanced acetone sensing properties of Co3O4 nanosheets with highly exposed (111) planes, J. Mater. Sci. Mater. Electron. 27 (2016) 2086-2095.

[144] B. Geng, F. Zhan, C. Fang, N. Yu, A facile coordination compound precursor route to controlled synthesis of $\mathrm{Co} 3 \mathrm{O} 4$ nanostructures and their room-temperature gas sensing properties, J. Mater. Chem. 18 (2008) 4977-4984.

[145] H. Deng, H.R. Li, F. Wang, C. Yuan, S. Liu, P. Wang, L. Xie, Y. Sun, F. Chang, A high sensitive and low detection limit of formaldehyde gas sensor based on hierarchical flower-like $\mathrm{CuO}$ nanostructure fabricated by sol-gel method, J. Mater. Sci. Mater. Electron. 27 (2016) 6766-6772.

[146] T. Wang, Q. Xiao, Solvothermal synthesis and sensing properties of meso-macroporous hierarchical $\mathrm{CuO}$ microspheres composed of nanosheets, Mater. Chem. Phys. 139 (2013) 603-608.

[147] X. Jia, H. Fan, W. Yang, Hydrothermal synthesis and primary gas sensing properties of CuO nanosheets, J. Dispers. Sci. Technol. 31 (2010) 866-869.

[148] F. Zhang, A. Zhu, Y. Luo, Y. Tian, J. Yang, Y. Qin, CuO nanosheets for sensitive and selective determination of H2S with high recovery ability, J. Phys. Chem. C. 114 (2010) 19214-19219.

[149] J. Tan, X. Huang, Ultra-thin nanosheets-assembled hollowed-out hierarchical aFe2O3 nanorods: synthesis via an interface reaction route and its superior gas sensing properties, Sens. Actuators B Chem. 237 (2016) 159-166.

[150] Q. Hao, S. Liu, X. Yin, Z. Du, M. Zhang, L. Li, Y. Wang, T. Wang, Q. Li, Flexible morphology-controlled synthesis of mesoporous hierarchical a-Fe2O3 architectures and their gas-sensing properties, CrystEngComm 13 (2011) 806-812.

[151] K. Fan, J. Guo, L. Cha, Q. Chen, J. Ma, Atomic layer deposition of ZnO onto Fe2O3 nanoplates for enhanced H2S sensing, J. Alloys Compd. 698 (2017) 336-340.

[152] Z. D. Wei, L. Huang, X. Wang, S. Chuai, G. Lu Zhang, Hydrothermal synthesis of Ce-doped hierarchical flower-like In2O3 microspheres and their excellent gassensing properties, Sens. Actuators B Chem. 255 (2018) 1211-1219.

[153] D. Han, P. Song, H. Zhang, H. Yan, Q. Xu, Z. Yang, Q. Wang, Flower-like In2O3 hierarchical nanostructures: synthesis, characterization, and gas sensing properties, RSC Adv. 4 (2014) 50241-50248.

[154] W.-H. Zhang, W.-D. Zhang, Biomolecule-assisted synthesis and gas-sensing properties of porous nanosheet-based corundum In2O3 microflowers, J. Solid State Chem. 186 (2012) 29-35.

[155] X. Xu, X. Li, H. Zhang, C. Feng, C. Wang, F. Liu, Y. Sun, P. Sun, G. Lu, Synthesis, characterization and gas sensing properties of porous flower-like indium oxide nanostructures, RSC Adv. 5 (2015) 30297-30302.

[156] X. Xu, D. Wang, W. Wang, P. Sun, J. Ma, X. Liang, Y. Sun, Y. Ma, G. Lu, Porous hierarchical In2O3 nanostructures: hydrothermal preparation and gas sensing properties, Sens. Actuators B Chem. 171-172 (2012) 1066-1072.

[157] M. Cai, R. Li, F. Wang, X. Guo, Q. Bai, L. Sun, X. Han, Architecture of designed hollow indium oxide microspheres assembled by porous nanosheets with high gas sensing capacity, J. Alloys Compd. 729 (2017) 222-230.

[158] X. Wang, J. Su, H. Chen, G.-D. Li, Z. Shi, H. Zou, X. Zou, Ultrathin In2O3 nanosheets with uniform mesopores for highly sensitive nitric oxide detection, ACS Appl. Mater. Interfaces 9 (2017) 16335-16342.

[159] H. Sun, Z. Chu, D. Hong, G. Zhang, Y. Xie, L. Li, K. Shi, Three-dimensional hierarchical flower-like Mg-Al-layered double hydroxides: fabrication, characterization and enhanced sensing properties to NOx at room temperature, J. Alloys Compd. 658 (2016) 561-568.

[160] A. Sanger, A. Kumar, A. Kumar, R. Chandra, Highly sensitive and selective hydrogen gas sensor using sputtered grown Pd decorated MnO2 nanowalls, Sensors Actuators B Chem. 234 (2016) 8-14.

[161] X. Tian, L. Yang, X. Qing, K. Yu, X. Wang, Trace level detection of hydrogen gas using birnessite-type manganese oxide, Sens. Actuators B Chem. 207 (2015) 34-42.

[162] Y. Liu, W. Zeng, Facile synthesis of 3D flower-like MoO3 and its gas sensor application, J. Mater. Sci. Mater. Electron. 27 (2016) 12996-13001.

[163] F. Ji, X. Ren, X. Zheng, Y. Liu, L. Pang, J. Jiang, S. (Frank) Liu, 2D-MoO3 nanosheets for superior gas sensors, Nanoscale 8 (2016) 8696-8703.

[164] M.M.Y.A. Alsaif, S. Balendhran, M.R. Field, K. Latham, W. Wlodarski, J.Z. Ou, K. Kalantar-zadeh, Two dimensional a-MoO3 nanoflakes obtained using solvent assisted grinding and sonication method: application for $\mathrm{H} 2$ gas sensing, Sens.
Actuators B Chem. 192 (2014) 196-204.

[165] D. Hong, J. Zhang, A.U. Rehman, L. Gong, J. Zhou, K. Kan, L. Li, K. Shi, One-step synthesis of hierarchical Ni-Fe-Al layered double hydroxide with excellent sensing properties for NOx at room temperature, RSC Adv. 6 (2016) 103192-103198.

[166] Y. Zhang, W. Zeng, New insight into gas sensing performance of nanoneedle-assembled and nanosheet-assembled hierarchical NiO nanoflowers, Mater. Lett. 195 (2017) 217-219.

[167] S. Liu, W. Zeng, T. Chen, Synthesis of hierarchical flower-like NiO and the influence of surfactant, Phys. E 85 (2017) 13-18.

[168] R. Miao, W. Zeng, Hydrothermal synthesis of flake-flower NiO architectures: structure, growth and gas-sensing properties, Mater. Lett. 171 (2016) 200-203.

[169] H. Gao, D. Wei, P. Lin, C. Liu, P. Sun, K. Shimanoe, N. Yamazoe, G. Lu, The design of excellent xylene gas sensor using Sn-doped NiO hierarchical nanostructure, Sensors Actuators B Chem. 253 (2017) 1152-1162.

[170] C. Wang, X. Cheng, X. Zhou, P. Sun, X. Hu, K. Shimanoe, G. Lu, N. Yamazoe, Hierarchical a-Fe2O3/NiO composites with a hollow structure for a gas sensor, ACS Appl. Mater. Interfaces 6 (2014) 12031-12037.

[171] G. Zhu, Y. Liu, C. Xi, C. Bao, H. Xu, X. Shen, X. Zhu, Polymer guided synthesis of Ni $(\mathrm{OH}) 2$ with hierarchical structure and their application as the precursor for sensing materials, CrystEngComm 15 (2013) 9189.

[172] C. Zhao, J. Fu, Z. Zhang, E. Xie, Enhanced ethanol sensing performance of porous ultrathin NiO nanosheets with neck-connected networks, RSC Adv. 3 (2013) 4018-4023.

[173] H.-J. Kim, J.-W. Yoon, K.-I. Choi, H.W. Jang, A. Umar, J.-H. Lee, Ultraselective and sensitive detection of xylene and toluene for monitoring indoor air pollution using Cr-doped NiO hierarchical nanostructures, Nanoscale 5 (2013) 7066-7073.

[174] K. Tian, X.-X. Wang, H.-Y. Li, R. Nadimicherla, X. Guo, Lotus pollen derived 3dimensional hierarchically porous $\mathrm{NiO}$ microspheres for NO2 gas sensing, Sens. Actuators B Chem. 227 (2016) 554-560.

[175] L. Lin, T. Liu, B. Miao, W. Zeng, Hydrothermal fabrication of uniform hexagonal NiO nanosheets: structure, growth and response, Mater. Lett. 102-103 (102) (2013) 43-.

[176] S. Wang, D. Huang, S. Xu, W. Jiang, T. Wang, J. Hu, N. Hu, Y. Su, Y. Zhang, Z. Yang, Two-dimensional NiO nanosheets with enhanced room temperature NO2 sensing performance via Al doping, Phys. Chem. Chem. Phys. 19 (2017) 19043-19049.

[177] G. Li, X. Wang, H. Ding, T. Zhang, A facile synthesis method for Ni(OH)2 ultrathin nanosheets and their conversion to porous $\mathrm{NiO}$ nanosheets used for formaldehyde sensing, RSC Adv. 2 (2012) 13018-13023.

[178] N.D. Hoa, S.A. El-Safty, Synthesis of mesoporous $\mathrm{NiO}$ nanosheets for the detection of toxic NO2 gas, Chem. - A Eur. J. 17 (2011) 12896-12901.

[179] C. Wang, W. Zeng, T. Chen, Facile synthesis of thin nanosheet assembled flowerlike NiO-ZnO composite and its ethanol-sensing performance, J. Mater. Sci. Mater. Electron. 28 (2017) 222-227.

[180] M. Bao, Y. Chen, F. Li, J. Ma, T. Lv, Y. Tang, L. Chen, Z. Xu, T. Wang, Plate-like p-n heterogeneous $\mathrm{NiO} / \mathrm{WO} 3$ nanocomposites for high performance room temperature NO2 sensors, Nanoscale 6 (2014) 4063-4066.

[181] Y. Liu, Y. Jiao, Z. Zhang, F. Qu, A. Umar, X. Wu, Hierarchical SnO2 nanostructure made of intermingled ultrathin nanosheets for environmental remediation smart gas sensor, and supercapacitor applications, ACS Appl. Mater. Interfaces 6 (2014) $2174-2184$

[182] J. Tian, J. Wang, Y. Hao, H. Du, X. Li, Toluene sensing properties of porous Pdloaded flower-like SnO2 microspheres, Sens. Actuators B Chem. 202 (2014) 795-802.

[183] J. Hu, Y. Wang, W. Wang, Y. Xue, P. Li, K. Lian, L. Chen, W. Zhang, S. Zhuiykov, Enhancement of the acetone sensing capabilities to ppb detection level by Fedoped three-dimensional $\mathrm{SnO} 2$ hierarchical microstructures fabricated via a hydrothermal method, J. Mater. Sci. 52 (2017) 11554-11568.

[184] C. Wang, W. Zeng, New insights into multi-hierarchical nanostructures with sizecontrollable blocking units for their gas sensing performance, J. Mater. Sci. Mater. Electron. 28 (2017) 10847-10852.

[185] Y. Li, T. Liu, H. Zhang, New insight into gas sensing performance of nanoneedleassembled and nanosheet-assembled hierarchical SnO2 structures, Mater. Lett. 176 (2016) 9-12.

[186] W.X. Jin, S.Y. Ma, Z.Z. Tie, J.J. Wei, J. Luo, X.H. Jiang, T.T. Wang, W.Q. Li, L. Cheng, Y.Z. Mao, One-step synthesis and highly gas-sensing properties of hierarchical Cu-doped SnO2 nanoflowers, Sens. Actuators B Chem. 213 (2015) 171-180.

[187] W.X. Jin, S.Y. Ma, A.M. Sun, J. Luo, L. Cheng, W.Q. Li, Z.Z. Tie, X.H. Jiang, T.T. Wang, Synthesis of hierarchical $\mathrm{SnO} 2$ nanoflowers and their high gas-sensing properties, Mater. Lett. 143 (2015) 283-286.

[188] H. Zhang, W. Zeng, J. Hao, Y. Li, B. Miao, Hydrothermal synthesis of flower-like SnO2 architectures with superior gas sensing properties, Mater. Lett. 145 (2015) 133-136.

[189] L. Cheng, S.Y. Ma, T.T. Wang, J. Luo, Synthesis and enhanced acetone sensing properties of 3D porous flower-like SnO2 nanostructures, Mater. Lett. 143 (2015) $84-87$.

[190] W. Zhang, W. Zeng, B. Miao, Z. Wang, Effect of the sheet thickness of hierarchical SnO2 on the gas sensing performance, Appl. Surf. Sci. 355 (2015) 631-637.

[191] X. Kuang, T. Liu, W. Wang, S. Hussain, X. Peng, Controlled synthesis of SnO2 hierarchical architectures made of ultrathin nanoflakes for enhanced ethanol gas sensing properties, Appl. Surf. Sci. 351 (2015) 1087-1093.

[192] X.H. Jiang, S.Y. Ma, A.M. Sun, Z.M. Zhang, W.X. Jin, T.T. Wang, W.O. Li, X.L. Xu, J. Luo, L. Cheng, Y.Z. Mao, M. Zhang, Hydrothermal self-assembly of novel porous flower-like $\mathrm{SnO} 2$ architecture and its application in ethanol sensor, Appl. Surf. Sci. 355 (2015) 1192-1200. 
[193] W.X. Jin, S.Y. Ma, Z.Z. Tie, W.Q. Li, J. Luo, L. Cheng, X.L. Xu, T.T. Wang, X.H. Jiang, Y.Z. Mao, Synthesis of hierarchical SnO2 nanoflowers with enhanced acetic acid gas sensing properties, Appl. Surf. Sci. 353 (2015) 71-78.

[194] Q. Zhao, D. Ju, X. Deng, J. Huang, B. Cao, X. Xu, Morphology-modulation of SnO2 hierarchical architectures by Zn doping for glycol gas sensing and photocatalytic applications, Sci. Rep. 5 (2015) 7874.

[195] H. Chen, Q. Wang, C. Kou, Y. Sui, Y. Zeng, F. Du, One-pot synthesis and improved sensing properties of hierarchical flowerlike $\mathrm{SnO} 2$ assembled from sheet and ultrathin rod subunits, Sens. Actuators B Chem. 194 (2014) 447-453.

[196] Y. Guan, D. Wang, X. Zhou, P. Sun, H. Wang, J. Ma, G. Lu, Hydrothermal preparation and gas sensing properties of $\mathrm{Zn}$-doped $\mathrm{SnO} 2$ hierarchical architectures, Sens. Actuators B Chem. 191 (2014) 45-52.

[197] L. Wang, S. Wang, Y. Wang, H. Zhang, Y. Kang, W. Huang, Synthesis of hierarchical $\mathrm{SnO} 2$ nanostructures assembled with nanosheets and their improved gas sensing properties, Sens. Actuators B Chem. 188 (2013) 85-93.

[198] W. Zeng, Q. He, K. Pan, Y. Wang, Synthesis of multifarious hierarchical flower-like SnO2 and their gas-sensing properties, Phys. E 54 (2013) 313-318.

[199] Y. Zeng, Y. Bing, C. Liu, W. Zheng, G. Zou, Self-assembly of hierarchical ZnSnO3SnO2 nanoflakes and their gas sensing properties, Trans. Nonferrous Met. Soc. China. 22 (2012) 2451-2458.

[200] P. Sun, W. Zhao, Y. Cao, Y. Guan, Y. Sun, G. Lu, Porous SnO2 hierarchical nanosheets: hydrothermal preparation, growth mechanism, and gas sensing properties, CrystEngComm 13 (2011) 3718-3724.

[201] J. Guo, J. Zhang, H. Gong, D. Ju, B. Cao, Au nanoparticle-functionalized 3D SnO2 microstructures for high performance gas sensor, Sens. Actuators B Chem. 226 (2016) 266-272.

[202] L. Liu, P. Song, Q. Wei, X. Zhong, Z. Yang, Q. Wang, Synthesis of porous SnO2 hexagon nanosheets loaded with Au nanoparticles for high performance gas sensors, Mater. Lett. 201 (2017) 211-215.

[203] S. Cao, W. Zeng, Z. Zhu, X. Peng, Synthesis of SnO2 nanostructures from 1D to 3D via a facile hydrothermal method and their gas sensing properties, J. Mater. Sci. Mater. Electron. 26 (2015) 1820-1826.

[204] M.-H. Xu, F.-S. Cai, J. Yin, Z.-H. Yuan, L.-J. Bie, Facile synthesis of highly ethanolsensitive $\mathrm{SnO} 2$ nanosheets using homogeneous precipitation method, Sensors Actuators B Chem. 145 (2010) 875-878.

[205] Z. Lou, L. Wang, R. Wang, T. Fei, T. Zhang, Synthesis and ethanol sensing properties of SnO2 nanosheets via a simple hydrothermal route, Solid. State. Electron. 76 (2012) 91-94.

[206] P. Sun, Y. Cao, J. Liu, Y. Sun, J. Ma, G. Lu, Dispersive SnO2 nanosheets: hydrothermal synthesis and gas-sensing properties, Sens. Actuators B Chem. 156 (2011) 779-783.

[207] X.H. Yang, H. Xie, H.T. Fu, X.Z. An, X.C. Jiang, A.B. Yu, Synthesis of hierarchical nanosheet-assembled V2O5 microflowers with high sensing properties towards amines, RSC Adv. 6 (2016) 87649-87655.

[208] X. Rui, Z. Lu, Z. Yin, D.H. Sim, N. Xiao, T.M. Lim, H.H. Hng, H. Zhang, Q. Yan, Oriented molecular attachments through sol-gel chemistry for synthesis of ultrathin hydrated vanadium pentoxide nanosheets and their applications, Small 9 (2013) 716-721.

[209] W. Zeng, H. Zhang, Z. Wang, Effects of different petal thickness on gas sensing properties of flower-like WO3. H2O hierarchical architectures, Appl. Surf. Sci. 347 (2015) 73-78.

[210] Z. Liu, B. Liu, W. Xie, H. Li, R. Zhou, Q. Li, T. Wang, Enhanced selective acetone sensing characteristics based on Co-doped WO3 hierarchical flower-like nanostructures assembled with nanoplates, Sens. Actuators B Chem. 235 (2016) 614-621.

[211] S. Wei, Y. Xing, Y. Li, Y. Zhao, W. Du, M. Zhou, Preparation and gas sensing properties of flower-like WO3 hierarchical architecture, Vacuum 129 (2016) $13-19$.

[212] Y. Yu, W. Zeng, H. Zhang, Hydrothermal synthesis of assembled WO3. H2O nanoflowers with enhanced gas sensing performance, Mater. Lett. 171 (2016) $162-165$.

[213] D. Meng, G. Wang, X. San, Y. Song, Y. Shen, Y. Zhang, K. Wang, F. Meng, Synthesis of WO3 flower-like hierarchical architectures and their sensing properties, J. Alloys Compd. 649 (2015) 731-738.

[214] C.-S. Wu, Hydrothermal fabrication of WO3 hierarchical architectures: structure, growth and response, Nanomaterials 5 (2015) 1250-1255.

[215] J. Li, X. Liu, J. Cui, J. Sun, Hydrothermal synthesis of self-assembled hierarchical tungsten oxides hollow spheres and their gas sensing properties, ACS Appl. Mater. Interfaces 7 (2015) 10108-10114.

[216] C. Wang, X. Li, C. Feng, Y. Sun, G. Lu, Nanosheets assembled hierarchical flowerlike WO3 nanostructures: synthesis, characterization, and their gas sensing properties, Sens. Actuators B Chem. 210 (2015) 75-81.

[217] C. Wang, R. Sun, X. Li, Y. Sun, P. Sun, F. Liu, G. Lu, Hierarchical flower-like WO3 nanostructures and their gas sensing properties, Sens. Actuators B Chem. 204 (2014) 224-230.

[218] W. Zeng, Y. Li, H. Zhang, Hierarchical WO3 porous microspheres and their sensing properties, J. Mater. Sci. Mater. Electron. 25 (2014) 1512-1516.

[219] W. Zeng, Y. Li, B. Miao, K. Pan, Hydrothermal synthesis and gas sensing properties of WO3. H2O with different morphologies, Phys. E 56 (2014) 183-188.

[220] B. Xiao, Q. Zhao, C. Xiao, T. Yang, P. Wang, F. Wang, X. Chen, M. Zhang, Lowtemperature solvothermal synthesis of hierarchical flower-like WO3 nanostructures and their sensing properties for H2S, CrystEngComm 17 (2015) $5710-5716$.

[221] T. Yang, H. Tian, Y. Zhang, C. Li, Chemical stability of 2D-nanostructured WO3 in hydrogen sensing under varied operation temperature, Nano 11 (2016) 1650092.

[222] M.B. Rahmani, M.H. Yaacob, Y.M. Sabri, Hydrogen sensors based on 2D WO3 nanosheets prepared by anodization, Sen. Actuators B Chem. 251 (2017) 57-64.

[223] Z. Wang, D. Wang, J. Sun, Controlled synthesis of defect-rich ultrathin two-dimensional WO3 nanosheets for NO2 gas detection, Sens. Actuators B Chem. 245 (2017) 828-834.

[224] M. Breedon, P. Spizzirri, M. Taylor, J. du Plessis, D. McCulloch, J. Zhu, Z. Yu, C. Rix, W. Wlodarski, K. Kalantar-zadeh, Synthesis of nanostructured tungsten oxide thin films: a simple, controllable, inexpensive, aqueous sol-gel method, Cryst. Growth Des. 10 (2010) 430-439.

[225] A. Boudiba, C. Zhang, C. Bittencourt, P. Umek, M.-G. Olivier, R. Snyders, M. Debliquy, Hydrothermal synthesis of two dimensional WO3 nanostructures for NO2 detection in the ppb-level, Procedia Eng. 47 (2012) 228-231.

[226] S.S. Kalanur, J. Heo, I.-H. Yoo, H. Seo, 2-D WO3 decorated with Pd for rapid gasochromic and electrical hydrogen sensing, Int. J. Hydrogen Energy 42 (2017) $16901-16908$

[227] X. Xie, X. Wang, J. Tian, X. Song, N. Wei, H. Cui, Growth of porous ZnO single crystal hierarchical architectures with ultrahigh sensing performances to ethanol and acetone gases, Ceram. Int. 43 (2017) 1121-1128.

[228] C. Peng, J. Guo, W. Yang, C. Shi, M. Liu, Y. Zheng, J. Xu, P. Chen, T. Huang, Y. Yang, Synthesis of three-dimensional flower-like hierarchical ZnO nanostructure and its enhanced acetone gas sensing properties, J. Alloys Compd. 654 (2016) 371-378.

[229] L. Zhang, J. Zhao, H. Lu, L. Li, J. Zheng, J. Zhang, H. Li, Z. Zhu, Highly sensitive and selective dimethylamine sensors based on hierarchical $\mathrm{ZnO}$ architectures composed of nanorods and nanosheet-assembled microspheres, Sens. Actuators B Chem. 171-172 (2012) 1101-1109.

[230] Z. Lin, F. Guo, C. Wang, X. Wang, K. Wang, Y. Qu, Preparation and sensing properties of hierarchical 3D assembled porous $\mathrm{ZnO}$ from zinc hydroxide carbonate, RSC Adv. 4 (2014) 5122-5129.

[231] X. Liu, J. Zhang, T. Yang, L. Wang, Y. Kang, S. Wang, S. Wu, Self-assembled hierarchical flowerlike $\mathrm{ZnO}$ architectures and their gas-sensing properties, Powder Technol. 217 (2012) 238-244.

[232] L. Zhang, J. Zhao, H. Lu, L. Li, J. Zheng, H. Li, Z. Zhu, Facile synthesis and ultrahigh ethanol response of hierarchically porous $\mathrm{ZnO}$ nanosheets, Sens. Actuators B Chem. 161 (2012) 209-215.

[233] M. Chen, Z. Wang, D. Han, F. Gu, G. Guo, High-sensitivity NO2 gas sensors based on flower-like and tube-like ZnO nanomaterials, Sens. Actuators B Chem. 157 (2011) 565-574.

[234] P.-Y. Qiao, L.-X. Zhang, M.-Y. Zhu, Y.-Y. Yin, Z.-W. Zhao, H.-N. Sun, J.-Y. Dong, L.$\mathrm{J}$. Bie, Acetylene sensing enhancement of mesoporous $\mathrm{ZnO}$ nanosheets with morphology and defect induced structural sensitization, Sens. Actuators B Chem. 250 (2017) 189-197.

[235] W. Guo, T. Liu, H. Zhang, R. Sun, Y. Chen, W. Zeng, Z. Wang, Gas-sensing performance enhancement in $\mathrm{ZnO}$ nanostructures by hierarchical morphology, Sens. Actuators B Chem. 166-167 (2012) 492-499.

[236] A.S.M. Iftekhar Uddin, K.-W. Lee, G.-S. Chung, Acetylene gas sensing properties of an $\mathrm{Ag}$-loaded hierarchical $\mathrm{ZnO}$ nanostructure-decorated reduced graphene oxide hybrid, Sens. Actuators B Chem. 216 (2015) 33-40.

[237] M.R. Alenezi, T.H. Alzanki, A.M. Almeshal, A.S. Alshammari, M.J. Beliatis, S.J. Henley, S.R.P. Silva, Hierarchically designed $\mathrm{ZnO}$ nanostructure based high performance gas sensors, RSC Adv. 4 (2014) 49521-49528.

[238] Z. Jing, J. Zhan, Fabrication and gas-sensing properties of porous ZnO nanoplates, Adv. Mater. 20 (2008) 4547-4551.

[239] R. Zhang, L. Wang, J. Deng, T. Zhou, Z. Lou, T. Zhang, Hierarchical structure with heterogeneous phase as high performance sensing materials for trimethylamine gas detecting, Sens. Actuators B Chem. 220 (2015) 1224-1231.

[240] G. Zhu, Y. Liu, H. Xu, Y. Chen, X. Shen, Z. Xu, Photochemical deposition of Ag nanocrystals on hierarchical $\mathrm{ZnO}$ microspheres and their enhanced gas-sensing properties, CrystEngComm 14 (2012) 719-725.

[241] X. Liu, J. Zhang, L. Wang, T. Yang, X. Guo, S. Wu, S. Wang, 3D hierarchically porous $\mathrm{ZnO}$ structures and their functionalization by Au nanoparticles for gas sensors, J. Mater. Chem. 21 (2011) 349-356.

[242] J. Li, H. Fan, X. Jia, Multilayered ZnO nanosheets with 3D porous architectures: synthesis and gas sensing application, J. Phys. Chem. C 114 (2010) 14684-14691.

[243] L. Yu, F. Guo, S. Liu, B. Yang, Y. Jiang, L. Qi, X. Fan, Both oxygen vacancies defects and porosity facilitated $\mathrm{NO} 2$ gas sensing response in $2 \mathrm{D} \mathrm{ZnO}$ nanowalls at room temperature, J. Alloys Compd. 682 (2016) 352-356.

[244] Y. Zhu, Y. Wang, G. Duan, H. Zhang, Y. Li, G. Liu, L. Xu, W. Cai, In situ growth of porous $\mathrm{ZnO}$ nanosheet-built network film as high-performance gas sensor, Sens. Actuators B Chem. 221 (2015) 350-356.

[245] L. Yu, J. Wei, Y. Luo, Y. Tao, M. Lei, X. Fan, W. Yan, P. Peng, Dependence of Al3 + on the growth mechanism of vertical standing $\mathrm{ZnO}$ nanowalls and their NO2 gas sensing properties, Sens. Actuators B Chem. 204 (2014) 96-101.

[246] L. Yu, F. Guo, Z. Liu, S. Liu, B. Yang, M.-L. Yin, X. Fan, Facile synthesis of three dimensional porous $\mathrm{ZnO}$ films with mesoporous walls and gas sensing properties, Mater. Charact. 112 (2016) 224-228.

[247] X.-L. Cheng, Z. Rong, X.-F. Zhang, Y.-M. Xu, S. Gao, H. Zhao, L.-H, Huo, In situ assembled $\mathrm{ZnO}$ flower sensors based on porous nanofibers for rapid ethanol sensing, Sens. Actuators B Chem. 188 (2013) 425-432.

[248] Y. Al-Hadeethi, A. Umar, S.H. Al-Heniti, R. Kumar, S.H. Kim, X. Zhang, 2D Sndoped $\mathrm{ZnO}$ ultrathin nanosheet networks for enhanced acetone gas sensing application, Ceram. Int. 43 (2017) 2418-2423.

[249] E. Modaresinezhad, S. Darbari, Realization of a room-temperature/self-powered humidity sensor, based on ZnO nanosheets, Sens. Actuators B Chem. 237 (2016) 358-366.

[250] D. Ju, H. Xu, J. Zhang, J. Guo, B. Cao, Direct hydrothermal growth of ZnO nanosheets on electrode for ethanol sensing, Sens. Actuators B Chem. 201 (2014) 
444-451.

[251] F. Fan, P. Tang, Y. Wang, Y. Feng, A. Chen, R. Luo, D. Li, Facile synthesis and gas sensing properties of tubular hierarchical $\mathrm{ZnO}$ self-assembled by porous nanosheets, Sens. Actuators B Chem. 215 (2015) 231-240.

[252] J. Zhou, F. Gong, H. Wang, Y. Xiao, F. Li, W. Mai, 3D mace-like hierarchical ZnO nanoarchitecture constructed with microrod bundles and porous single-crystalline nanosheets for acetone sensors with enhanced performances, Mater. Sci. Eng. B. 225 (2017) 68-74.

[253] J. Liu, Z. Guo, F. Meng, T. Luo, M. Li, J. Liu, Novel porous single-crystalline ZnO nanosheets fabricated by annealing ZnS(en)0.5 (en = ethylenediamine) precursor. Application in a gas sensor for indoor air contaminant detection, Nanotechnology 20 (2009) 125501.

[254] Y. Xiao, L. Lu, A. Zhang, Y. Zhang, L. Sun, L. Huo, F. Li, Highly enhanced acetone sensing performances of porous and single crystalline $\mathrm{ZnO}$ nanosheets: high percentage of exposed (100) facets working together with surface modification with Pd nanoparticles, ACS Appl. Mater. Interfaces. 4 (2012) 3797-3804.

[255] M. Ali, C.Y. Wang, C.-C. Röhlig, V. Cimalla, T. Stauden, O. Ambacher, NOx sensing properties of In2O3 thin films grown by MOCVD, Sens. Actuators B Chem. 129 (2008) 467-472.

[256] T. Takada, K. Suzuki, M. Nakane, Highly sensitive ozone sensor, Sens. Actuators B Chem. 13-14 (1993) 404-407.

[257] A. Kusior, M. Radecka, L. Zych, K. Zakrzewska, A. Reszka, B.J. Kowalski, Sensitization of TiO2/SnO2 nanocomposites for gas detection, Sens. Actuators B Chem. 189 (2013) 251-259.

[258] X. Wang, Y. Sang, D. Wang, S. Ji, H. Liu, Enhanced gas sensing property of SnO2 nanoparticles by constructing the $\mathrm{SnO} 2-\mathrm{TiO} 2$ nanobelt heterostructure, J. Alloys Compd. 639 (2015) 571-576.

[259] S. Tian, D. Zeng, X. Peng, S. Zhang, C. Xie, Processing-microstructure-property correlations of gas sensors based on $\mathrm{ZnO}$ nanotetrapods, Sens. Actuators B Chem. 181 (2013) 509-517.

[260] Y. Zhou, Y. Jiang, T. Xie, H. Tai, G. Xie, A novel sensing mechanism for resistive gas sensors based on layered reduced graphene oxide thin films at room temperature, Sens. Actuators B Chem. 203 (2014) 135-142.

[261] A.P. Lee, B.J. Reedy, Temperature modulation in semiconductor gas sensing, Sens. Actuators B Chem. 60 (1999) 35-42.
[262] F. Röck, N. Barsan, U. Weimar, Electronic nose: current status and future trends, Chem. Rev. 108 (2008) 705-725.

[263] R. Zhang, W. Pang, Z. Feng, X. Chen, Y. Chen, Q. Zhang, H. Zhang, C. Sun, J.J. Yang, D. Zhang, Enabling selectivity and fast recovery of $\mathrm{ZnO}$ nanowire gas sensors through resistive switching, Sens. Actuators B Chem. 238 (2017) 357-363.

[264] P. Uthirakumar, S. Muthulingam, R. Khan, J.H. Yun, H.-S. Cho, I.-H. Lee, Surfactant-free synthesis of leaf-like hierarchical CuO nanosheets as a UV light filter, Mater. Lett. 156 (2015) 191-194.

[265] D. Kato, M. Kunitake, M. Nishizawa, T. Matsue, F. Mizutani, Amperometric nitric oxide microsensor using two-dimensional cross-linked Langmuir-Blodgett films of polysiloxane copolymer, Sens. Actuators B Chem. 108 (2005) 384-388.

[266] D. Kato, M. Kunitake, M. Nishizawa, T. Matsue, F. Mizutani, Electrochemical nitric oxide microsensors based on two-dimensional cross-linked polymeric LB films of oligo(dimethylsiloxane) copolymer, Electrochim. Acta. 51 (2005) 938-942.

[267] P. Tarttelin Hernández, S.M.V. Hailes, I.P. Parkin, Hydrocarbon detection with metal oxide semiconducting gas sensors modified by overlayer or admixture of zeolites Na-A, H-Y and H-ZSM-5, Sens. Actuators B Chem. 242 (2017) 1281-1295.

[268] J.N. Anker, W.P. Hall, O. Lyandres, N.C. Shah, J. Zhao, R.P. van Duyne, Biosensing with plasmonic nanosensors, Nat. Mater. 7 (2008) 442-453.

Dr. Petra Dral obtained her Master of Science degree in Chemical Engineering cum laude at the University of Twente, The Netherlands, with a focus on molecules and materials and a special interest in metal oxide nanosheets. She then obtained her $\mathrm{PhD}$ degree under the supervision of Professor Johan ten Elshof on the topic of water sensitivity and microporosity in organosilica glasses. Currently she is working as a materials and process engineer in industry.

Dr. Johan E. ten Elshof is professor of Inorganic \& Hybrid Nanomaterials Chemistry at the MESA + Institute for Nanotechnology at the University of Twente in Enschede, Netherlands. His research focuses on the development of novel metal oxide \& organicinorganic nanomaterials, nanopatterns and nanostructures from colloidal and chemica solutions, with specific emphasis on low-dimensional materials like flexible ceramic nanofibers, metal oxide nanosheets and oxide nanowires, and with main application areas in the fields of energy materials and nanoelectronics. 